\title{
ANALYTICAL CHEMISTRY OF ABIOLOGICAL AND BIOLOGICAL MOLECULES BY GAS CHROMATOGRAPHY AND MASS SPECTROMETRY
}

\author{
Vivek Navale \\ Raytheon Information Technology and Scientific Services, \\ 4400 Forbes Boulevard, Lanham, Maryland, 20706, USA
}

TABLE OF CONTENTS

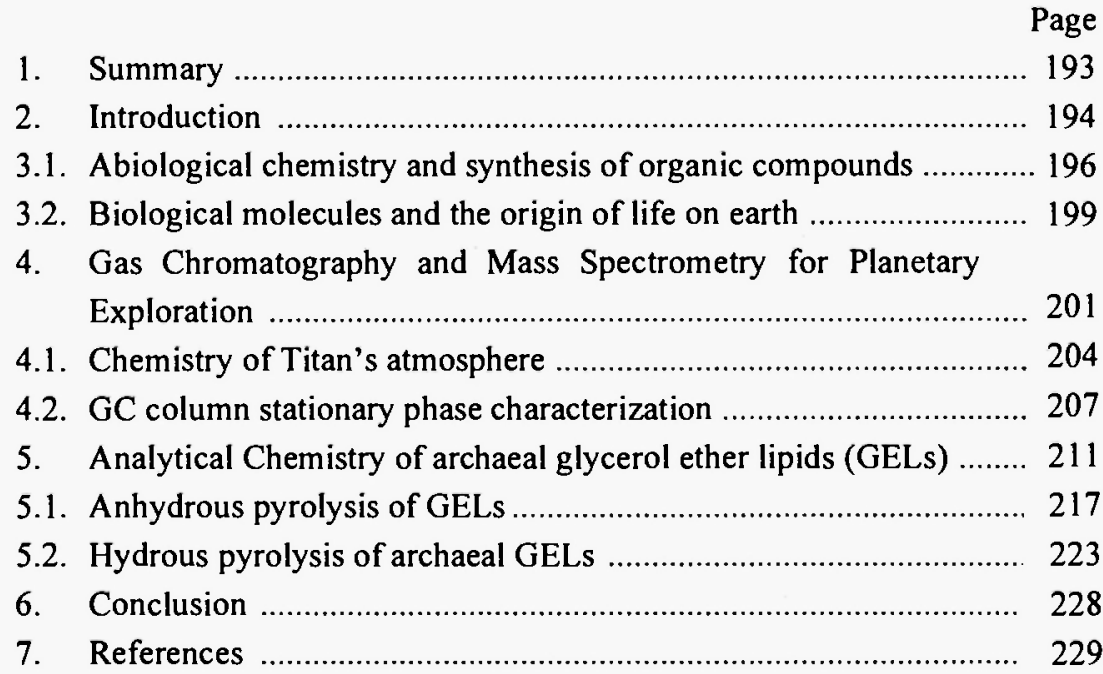

\section{SUMMARY}

The identification of abiological and biological molecules is of importance for understanding the chemical and biological processes occurring

\footnotetext{
* Correspondence address: Dr. Vivek Navale, NASA/Goddard Space Flight Center- Raytheon ITSS, Code 915, Greenbelt, MD, 20771, USA; Tel. (301) 614-6404, Fax. (301) 614-6406; E-mail: Vivek.Navale@gsfc.nasa.gov
} 
within the solar system. The explorations of planetary environments for the detection of organic compounds are being conducted by the gas chromatography and mass spectrometry (GC-MS) method.

In the year 2004, the Cassini-Huygens GC-MS instrument will provide for the first time in-situ multicomponent analysis of Titan's atmosphere. Three novel gas chromatographic columns will separate hydrocarbons, nitriles, $\mathrm{CO}$ and other constituents from a predominant $\mathrm{N}_{2}$ background, which will be mass analyzed by a multipurpose miniaturized mass spectrometer. It is likely that the results of this work can enhance our understanding of exobiology and the "origin of life."

The archaea are microorganisms that inhabit extreme environments on earth and could inhabit in other parts of the solar system. The cell membrane of these organisms contains uniquely identifiable isoprenoid glycerol ether lipids (GELs), which are reliable as biological markers. Determining the effect of thermal stress on archaeal GELs may provide a better understanding of long-term chemical changes, which GELs can undergo in a natural environment. Also, by characterizing the decomposition products of biological molecules, it may be possible to bridge the gap between chemical and biological evolution.

\section{INTRODUCTION}

The origin of the universe and the formation of the earliest living systems are two of the fundamental questions that have intrigued the human mind for centuries. Telescopic observations from earth and in space, such as the Hubble telescope, have detected light from galaxies billions of light-years away. The cosmic background explorer (COBE) experiments on satellites have detected the remnants of microwave radiation left over during the formation of the universe, and provided large scale images about the events of the cosmic beginnings $/ 1$.

To date, the best efforts to explain the wealth of modern astronomical and astrophysical data are embodied in a cosmological model, known as the "big bang" theory. The theory states that about 15 billion years ago, the universe emerged from a sea of matter and energy, which has been continuously expanding in a nearly homogeneous manner from its early hot dense state $/ 2 /$. This view of the universe is supported by the red-shift in the spectrum of different galaxies and the detection of more or less uniform three 
Kelvin microwave background radiation. However, many cosmological questions remain unresolved. For example, what was the universe like before it was expanding? (No observation has been possible beyond the moment at which the expansion began). How were the galaxies formed and what may happen in the distant future when the last of the stars exhaust the supply of nuclear fuel?

Despite some unknown facets of the universe, cosmochemical studies have shown that about $98 \%$ of the matter in the universe are made of hydrogen and helium. All other elements were synthesized by thermonuclear reactions during star formation and supernova explosions $/ 3$. The synthesis of carbon nuclide is important because living organisms on earth have a carbon-based chemistry. The carbon nuclide can also be considered as the starting point for the generation of other important elements, namely nitrogen, oxygen, sulfur and phosphorous, which are collectively known as the biogenic elements. These elements are thought to have combined with the atmospheres of cool carbon stars, and led to the formation of molecules such as formaldehyde, hydrogen cyanide and water. Approximately 100 molecules ( $75 \%$ of which are organic and the rest are inorganic) have been detected in interstellar space, and it is presently believed that similar molecules may have contributed to the formation of the solar system $/ 4 /$.

Among the planets of the solar system, earth is unique because its global atmosphere is oxygenic and it supports living organisms. However, prior to about 2 billion years ago, even earth's atmosphere was devoid of molecular oxygen. Comparative analysis with the known values of cosmic abundance of inert gases has indicated that earth's primary atmosphere was lost during the initial phase of planetary formation. It is presumed that the secondary atmosphere of earth was comprised of $\mathrm{CO}, \mathrm{N}_{2}$ and $\mathrm{CO}_{2}$ with minor contribution of reducing gases such as $\mathrm{CH}_{4}$ and $\mathrm{NH}_{3} / 5 /$.

The composition of earth's early atmosphere is debatable (strongly reducing versus neutral atmosphere), however, there is conclusive evidence that microorganisms existed on earth, as far back as 3.5 billion years ago /6/. The lack of unambiguous evidence of living organisms (active or relic) from other parts of the solar system leads to certain fundamental questions: Is biological activity unique to earth, or is it pervasive in the universe? The study of the origin, evolution and distribution of living organisms in the universe is termed as exobiology. An integral part of exobiological studies is the abiological synthesis of organic compounds in planetary environments, 
which is considered as one of the initial steps for the chemical evolution of self-replicating organisms.

\subsection{ABIOLOGICAL SYNTHESIS OF ORGANIC COMPOUNDS}

The first simulation experiment of planetary atmospheres was demonstrated by the classical work of Miller /7/. Exposing a mixture of methane, ammonia, water, and hydrogen to an electric discharge for a period of one week resulted in products that included amino acids i.e., glycine, alanine, $\beta$-alanine, aspartic acid and glutamic acid. Following this work, many attempts to retrace the path from a planetary atmosphere to biopolymers (polypeptides, lipids, and nucleic acids) were made. In the majority of these studies, two precursors namely formaldehyde and hydrogen cyanide were found to play a key role in the synthesis of biomolecules $/ 8$ /.

All 20 amino acids found in living organisms can be synthesized in the laboratory under reducing prebiotic conditions. The simulation experiments have also shown that amino acids, imidazole, and uracil can be formed in the absence of $\mathrm{CH}_{4}$ and $\mathrm{NH}_{3}$. Similar laboratory results were observed when different molar compositions of gaseous atmospheres of Titan, Jupiter, and cometary coma were exposed to cosmic radiation 19/. The study also indicated that aldehydes and HCN served as intermediate products, which in the presence of water formed amino and hydroxy nitriles and amino and hydroxy acids.

Adenine, an important nucleic acid component can be formed by electron irradiation of methane, ammonia, and water $/ 10 \%$. $\mathrm{HCN}$ was detected as an intermediate product in the above experiment. The formation of $\mathrm{HCN}$ as the primary intermediate product during adenine synthesis was also shown by using dilute ammonium cyanide solutions. Several biochemical monomers representative of living organisms have been synthesized under laboratory abiotic conditions $/ 11,12 /$.

The laboratory simulation experiments however, are constrained spatially and temporally, which places restrictions for extrapolating the results to planetary scale organic synthesis. It has been stated that for a gas irradiated by a source of energy, the important physical factors are pressure (which determines the ratio of uni-, bi-, and trimolecular processes), the form of energy, and to a lesser extent temperature (unless the reaction is strongly temperature dependent) /13/. In planetary stratospheres, such as Titan's 
(satellite of Saturn), the radiation chemistry occurs mainly at low pressures. The rate of energy input is relatively low, and probably a small fraction of the chemical bonds of the main atmospheric constituents may be broken. Since no real-time measurements of early earth's atmosphere is possible, exploring planets and their satellites with environments undergoing chemical evolution analogous to earth's ancient atmosphere may provide a better understanding of abiological synthesis of organic compounds. By making in-situ measurements of planetary atmospheres, it may be possible to bridge the gap between chemical and biological processes.

Assuming that biologically important monomers can be formed in planetary environments, an important step towards biological organization involves the formation of macromolecules. Fox and Harada have shown that at a temperature of 180 to $200^{\circ} \mathrm{C}$, the amino acid mixtures with high concentrations of glutamic acid or aspartic acid polymerize to yield a mixture of polypeptides containing 18 to 20 amino acids $/ 14 \%$. These types of polymers, called protenoids, resembled the amino acid content of biological polymers, and possessed molecular weights in the range of 3600 to $8600 \mathrm{Da}$ 115/. Also, synthesis of peptides from dilute solutions of amino acids has been accomplished by the use of condensing agents such as cyanamide and dicyanamide. Both of these compounds are reported as ultraviolet irradiation products of aqueous solution of $\mathrm{HCN}$, methane and ammonia $/ 16 /$. The condensing agents may promote the oligomerization process of peptides in a planetary environment. Recent studies have indicated that hot anaerobic aqueous amino acids solutions at $100^{\circ} \mathrm{C}$, in presence of $\mathrm{CO}, \mathrm{H}_{2} \mathrm{~S}$ and (Ni, Fe)S, can be oligomerized to peptides. $/ 17 /$.

Small amounts of oligonucleotides can also be formed by thermal phosphorylation (temperature of $150^{\circ} \mathrm{C}$ ) of nucleosides in the presence of inorganic phosphates. It was observed that the synthesis of adenosine was possible when dilute solutions of ribose, adenine, and phosphate were exposed to ultraviolet light $/ 18 /$. Under similar ultraviolet wavelengths, in the presence of cyanamide, ribose, deoxyribose, adenosine monophosphate (AMP), adenosine diphosphate (ADP), and adenosine triphosphate (ATP) were formed. Cyanamide has also been found to be an excellent condensing reagent for the synthesis of deoxynucleotides /19/. Figure 1 illustrates the possible modes of transformation of monomers to biopolymers $/ 20 \%$.

The association of biopolymers with amphiphilic lipids was probably a decisive step towards the origin of cellular organisms /21\%. Lipids are hydrophobic molecules that self assemble spontaneously into liposomes and 


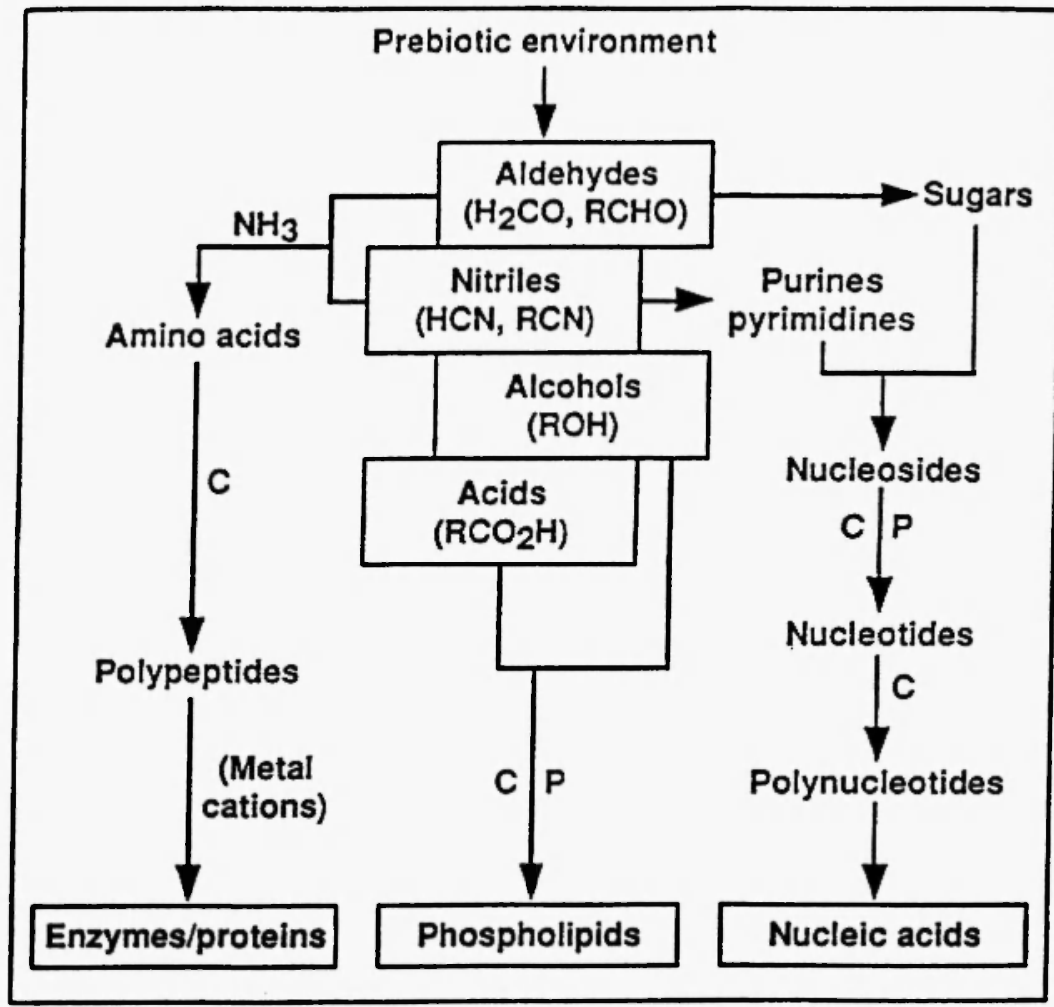

Fig: 1: is an outline of the possible routes of abiological synthesis of biomolecules. $\mathrm{HCN}$ and $\mathrm{CH}_{2} \mathrm{O}$ are important precursor molecules necessary for the formation of simple biomolecules. The symbol C, signifies that condensing agents are important for the formation of macromolecules. The requirement for inorganic phosphate is indicated by 'P' (reprinted from S. Chang, 1993, ref. /20/, with kind permission from Kluwer Academic Publishers).

microstructures, and are important components of cell membranes. For example, the two amphiphilic lipids phosphatidylcholine and phosphatidylethanolamine have been synthesized in the laboratory by combining fatty acids and glycerol in the presence of phosphate compounds $/ 22 \%$. Despite the formation of biopolymers in the laboratory, the mechanism of transformation from chemical to biological systems (i.e., the triggering of life) remains largely unknown $/ 23 /$. 


\subsection{BIOLOGICAL MARKERS AND EARLY LIFE ON EARTH}

Our current knowledge on the formation of the solar system indicates that significant amounts of organic inventory may have been represented by polycyclic aromatic hydrocarbons (PAHs). The PAHs are an abundant group of free organic molecules in the interstellar medium 124 , identified in several meteorites /25/, most notably in the ALH84001 meteorite where relic biogenic activity on Mars was related to these kinds of molecules $/ 26 /$. The PAHs were probably transported from interstellar space by meteoritic and cometary infall and may have accumulated during the late accretion period of Earth $/ 27$.

Recent laboratory photochemical investigations involving UV irradiation of PAHs in ice showed the formation of aromatic alcohols, ketones and ethers 128/. Other investigations of PAHs pyrene and fluoranthene (two of the many PAHs reported from meteorites) have shown that in an anaerobic environment, these molecules can capture light energy, drive photosensitive reactions to form amphilic molecules, and can self assemble into membranous bound structures known as "vesicles." These types of vesicles may have been capable of encapsulating macromolecules of primitive living systems /29/.

Although uncertainties in the mechanism of the origin of cellular organisms exist, stable isotopic studies of ancient rocks on earth have shown that biological activity may have commenced as far back as $\mathbf{3 . 8}$ billion years ago $/ 30,31$. In contrast to the organic inventory of early earth, the origin and evolution of living organisms produced a repertoire of biochemicals namely, proteins, carbohydrates, lipids and nucleic acids. Most of these molecules are relatively labile and are recycled effectively by microorganisms. It may be mentioned here that tiny fraction $(<1 \%)$ of the biomass produced on Earth, escapes the highly efficient process of microbial recycling, and undergoes condensation and polymerization reactions in sediments leading to the formation of disseminated organic matter, known as 'kerogen' $/ 32$.

Kerogen, a precursor of petroleum, is biological in origin. Hydrocarbons including the PAHs produced from kerogen are from physico-chemical changes (increasing temperature, geological time, and pressure). In essence, the primary mode of PAH formation in the later period of the earth history was by combustion of organic compounds with different degrees of thermal history and transport /33/. Because of the multiple modes of PAH formation, the usefulness of these types of molecules is limited as reliable biological markers /34/. 
A review of biological molecules related to the early life on earth has shown that certain important criteria need to be met for organic compounds to serve as biological markers $135 \%$. The requirements are (a) specificity of molecules to living organisms (in the present or past), with little change to the chemical structure of the biochemical produced in the organisms, (b) long-term chemical stability of the molecules with capability to resist microbial and geochemical alteration over an extended geological period, and (c) syngenecity of the biochemicals to the host rock.

Compared to proteins and amino acids, lipids are relatively resistant to biochemical and thermal degradation, and are more reliable as biomarkers. The specific classes of lipid biomarker compounds with reliable databases are pentacyclic triterpane hydrocarbons, hopanoids and steranes, and acyclic isoprenoid hydrocarbons $136 /$. These biomarkers are collectively known as terpenoid hydrocarbons, as they share a common structural unit called isoprene moiety $\left(\mathrm{C}_{5} \mathrm{H}_{8}\right)$. The terpenoids play a universal role in the formation of biomembranes, which are structural elements of cells. It is also presumed that structural changes in terpenoid biosynthesis by microorganisms may be correlated with environmental changes such as the presence of oxygen in the atmosphere $/ 37 \%$.

A wide variety of these biomarkers have been identified in oil-bearing sediments and sedimentary rocks. A systematic study of Precambrian sedimentary rocks (geological age ranging from 0.5 to 3.5 billion years) showed that only trace quantities of biomarkers - normal, isoprenoid, triterpane, and sterane hydrocarbons are identifiable from ancient rocks $/ 38$. The study revealed that with increasing geological age of the rock, sterane hydrocarbons (indicators of an oxygenic environment on earth) were less identifiable.

In hydrothermal vents of modern day environment, several extremophilic organisms, called the hyperthermophiles have been found. These types of microorganisms have been classified into the third phylogenetic domain, the archaea. The archaea are comprised of extremophilic prokaryotic organisms, which possess molecular and supramolecular structures of unusual intrinsic stability. These types of microbes might have dominated the anoxic environment of the early period in earth's evolution /39/. Lipids of the archaea are characterized by novel chemical structure which is formed by two or four ether links between two vicinyl hydroxyl groups of a glycerol or more complex polyol, and $\mathrm{C}_{20}, \mathrm{C}_{25}, \mathrm{C}_{40}$ isoprenoidic alcohols $/ 40 \%$. It is possible 
that these types of molecules may serve as reliable markers for identifying biological activity in other parts of the solar system.

In light of the above discussion, the following sections of the paper focus on the application of the gas chromatography and mass spectrometry methods for studying important abiological and biological molecules, which bear significance to the "origin of life."

\section{GAS CHROMATOGRAPHY AND MASS SPECTROMETRY FOR PLANETARY EXPLORATION}

GC-MS is the synergistic combination of two powerful analytical techniques, the gas chromatograph (GC), which separates components of a mixture in time, and the mass spectrometer (MS) that enables structural identification of each component. The fundamental concepts of GC and GC-MS for the analysis of a wide variety of compounds have been discussed extensively in several texts and reviews $141,42,43,44 \%$. Also, the various space-bound mass spectrometers deployed in the past have been reviewed in detail /45/. The current paper highlights the GC columns and the stationary phases used for in-situ analysis of planetary environments.

The first space mission to comprise gas chromatographs was the 1976 Viking mission to Mars. The GC system of the gas exchange (Gex) instrument contained two GC columns, an analytical column and a reference column. The stainless steel columns ( $7.6 \mathrm{~m}$ in length, $1.4 \mathrm{~mm}$ outer diameter) were packed with the Porapak $Q$ as the stationary phase. Helium was used as the carrier gas (flow rate of $13.5 \mathrm{~cm}^{3} / \mathrm{min}$ ) for analyzing permanent gases, noble gases, methane, carbon dioxide, hydrogen sulfide and nitrogen oxides. The GC sub-system of the Viking GC-MS contained a stainless steel column ( $2 \mathrm{~m}$ in length and $0.75 \mathrm{~mm}$ o.d.) packed with 60-80 mesh 2,6-diphenylp-oxide coated with poly-m-phenoxylene. A hydrogen carrier gas with a flow rate of $2 \mathrm{~mL} / \mathrm{min}$ was applied to provide separation of alcohols, hydrocarbons and amines $146 /$. The GC was interfaced with a double focusing magnetic sector mass spectrometer containing an electron impact (EI) ion source. The mass range of the Viking GC-MS instrument was from 12 to $125 \mathrm{amu}$. /47/. The Viking GC and GC-MS instruments were designed for a lander type spacecraft and were intended as biological experiments, to detect metabolic activity of microorganisms and identify the organic compounds in the soil. 
The soil samples analyzed by the GC-MS instrument did not detect organic compounds, which indicated paucity of biological activity on Mars.

The Venus probe instruments were designed to provide chemical analysis of the Venus environment during the descent of the spacecraft through the atmosphere. Miniaturization becomes essential for atmospheric probe type instruments because of significant engineering and experimental constraints placed on the atmospheric probe type of spacecraft. Shorter sample analysis time, low mass load, limited power and carrier gas volume are some of the experimental constraints imposed for probe type instruments.

The 1978 Pioneer-Venus GC instrument contained two packed columns. One column (dimensions $15.85 \mathrm{~m}$, length and $1.1 \mathrm{~mm}$, o.d.) packed with 100-120 mesh Porapak N stationary phase enabled the separation of neon, hydrogen, nitrogen, oxygen, argon, carbon monoxide, methane and krypton. The other column $(2.1 \mathrm{~m}$, length and $1.1 \mathrm{~mm}$, o.d.) was packed with $180-220$ mesh polydivinylbenzene to provide separation of carbon dioxide, hydrogen halides, ammonia, water, hydrogen sulfide, carbonyl sulfide, ethane and sulfur dioxide $/ 48 /$.

The GC instruments of 1978-1982 Venus missions (Venera missions 11 to 14) contained three serial columns each. The first column ( $2 \mathrm{~m}$, length) was packed with modified polysorb for separating hydrogen sulfide, carbonyl sulfide, sulfur dioxide, water and carbon dioxide. The second column $(2.5 \mathrm{~m}$, length) packed with molecular sieve provided separation of hydrogen, oxygen, nitrogen, carbon monoxide, helium, krypton and methane, and the third column was packed with reduced manganese to measure argon.

The 1985 Vega mission to Venus also contained three GC columns. Two of the columns were packed with a mixture of Porapak QS and Poarapak N, and the third column was packed with Porapak T. Helium was the mobile phase for analysis with one of the columns used whereas ultrapure nitrogen was the carrier gas for analysis with the other two columns. The columns provided separation of oxygen, carbon dioxide, carbonyl sulfide, hydrogen sulfide, sulfide dioxide, and water. The measurements made by the series of Venus GC instruments provided quantitative information on the atmospheric gases (listed above), and was also able to estimate the sulfuric acid content of the Venus clouds /48/.

All of the GC instruments deployed for the exploration of Venus missions contained packed columns. These types of columns can provide adequate separation of permanent and inert gases at relatively higher carrier gas flow rate (usually more than $10 \mathrm{~mL} / \mathrm{min}$ ) and elevated isothermal temperature 
(more than $50^{\circ} \mathrm{C}$ ). However, direct interface of conventional packed columns (column i.d. ranging from 2 to $4 \mathrm{~mm}$ ) to a mass spectrometer requires the use of a GC-MS interface. The high vacuum conditions needed for the operation of a mass spectrometer, necessitate the reduction of volumetric flow through the ion source and the mass analyzer. Hence, the Viking GC-MS instrument utilized a palladium alloy separator designed as the interface to eliminate the excess hydrogen carrier gas.

With the invention of open tubular columns (OTC), efficient separation of several organic compounds has been possible /49/. Compared to the packed columns, the OTC columns contain about 3 to $5 \%$ of stationary phase. Commonly, the stationary phase of an OTC is made of polysiloxane material, which is chemically bonded to the wall of a deactivated fused silica capillary column. Higher column efficiency and lower carrier gas flow rates are the advantages of the OTC columns. The partitioning (capacity factor) of methane and the inert gases between the mobile and the polysiloxane stationary phases is very small. Thus polysiloxane stationary phases are unable to resolve the low-molecular weight gases.

Separation of light hydrocarbons is possible by the porous layer open tubular (PLOT) type of column. The PLOT columns contain a porous layer of solid adsorbent deposited on the inner wall of a capillary column. The PoraPlot Q (porous polymer of styrene-divinyl benzene, Chrompack, Middleburg, Netherlands) fused silica column (10 m, L and $0.31 \mathrm{~mm}$, i.d.) can resolve a mixture of low-molecular weight hydrocarbons and nitriles within a 10-minute time interval $/ 50 /$. An isothermal temperature of $160{ }^{\circ} \mathrm{C}$, and a carrier gas flow rate in the range of $2 \mathrm{~mL} / \mathrm{min}$ was needed for the analysis. Compared to the PoraPlot $\mathrm{Q}$, the potassium chloride-deactivated alumina PLOT column ( $10 \mathrm{~m}, \mathrm{~L}, 0.32 \mathrm{~mm}$ i.d. and $5 \mu \mathrm{m} \mathrm{Al}_{2} \mathrm{O}_{3}$ film thickness) showed high retentivity for nitriles, even at a isothermal temperature of 150 ${ }^{\circ} \mathrm{C}$. Also, the nitrile peak shape on the latter phase was broad and asymmetric between the 15 to 30 minute time interval /51/. The separation of $\mathrm{CO}$ and $\mathrm{N}_{2}$ from hydrocarbons and nitriles has been made on a wide bore Molsieve 5 PLOT capillary column $(10 \mathrm{~m}, \mathrm{~L}, 0.53 \mathrm{~mm}$, i.d.) when isothermally heated to $90^{\circ} \mathrm{C}$ with a hydrogen carrier gas flow rate of $2 \mathrm{~mL} / \mathrm{min} / 52 /$.

For space applications, mechanical strength of the column is a very important consideration, and the ability to withstand spacecraft vibrations during launch is critical. The inner column wall of the PLOT columns is susceptible to disintegration during spacecraft vibration simulations. However, the wall coated open tubular capillary columns seem to be 
unaffected by such effects because the stationary phase is chemically bonded to the wall of the capillary column.

Under specified conditions (gas mixture without nitrogen and hydrogen as the carrier gas with an outlet flow rate of $0.6 \mathrm{~mL} / \mathrm{min}$ ), a $100 \%$ dimethyl polysiloxane (DMPS) stationary phase (CP-Sil-5 CB, Chrompack, Middleburg, Netherlands) OTC fused silica capillary columns provided separation of low molecular weight hydrocarbons $\left(\mathrm{C}_{1}-\mathrm{C}_{6}\right.$ hydrocarbons $)$ and nitriles $\left(\mathrm{C}_{1}-\mathrm{C}_{4}\right) / 53 /$. At an isothermal temperature of $20^{\circ} \mathrm{C}$, the analysis time was 35 minutes for the separation of hydrocarbons and nitriles. The temperature programming of the column from 20 to $80^{\circ} \mathrm{C}$ at the rate of $20^{\circ} \mathrm{C}$ / min (with an initial hold time of 4 minutes) reduced the time of analysis to 16 minutes. Under similar conditions, the nitriles also showed some improvement in selectivity when $5 \%$ phenyl $95 \%$ dimethyl polysiloxane (BPX5, Chrompack, Middleburg, Netherlands) column was used for analysis $154 /$.

\subsection{Chemistry of Titan's atmosphere}

In the solar system, Titan has a chemical composition that can be considered as the closest analogue to earth's early atmosphere. The predominant gaseous component of Titan is nitrogen with an estimated atmospheric surface pressure of about 1.5 bar (one and half times that of earth). The atmosphere is devoid of molecular oxygen. Methane is about one percent of the total atmosphere, water is in the form of ice and the surface temperature is $94 \mathrm{~K}$ 155/. The remote sensing measurements made by the Voyager infrared and ultraviolet spectrometers showed that the stratospheric region (80 to $200 \mathrm{~km}$ from surface) contains a series of hydrocarbons and nitriles, whereas the troposphere (below $70 \mathrm{~km}$ ) is composed of $\mathrm{CO}, \mathrm{Ar}, \mathrm{N}_{2}$, $\mathrm{H}_{2}$, and $\mathrm{CH}_{4}$. The temperature of the tropopause (region between strato- and troposphere) was inferred to be about $70 \mathrm{~K}$, which indicated that this region acts as a natural cold trap for gases present in troposphere. Figure 2 illustrates the variability in pressure and temperature in relation to changes with altitude of Titan's atmosphere. The hydrocarbons and nitriles observed in the stratosphere might have resulted from the photochemical reactions, and further condensation reaction lead to the formation of polyacetylenes and cyanide polymers that cause a thick smog-like haze in the atmosphere, popularly known as the "Titan haze" $156 /$. However, the processes and 


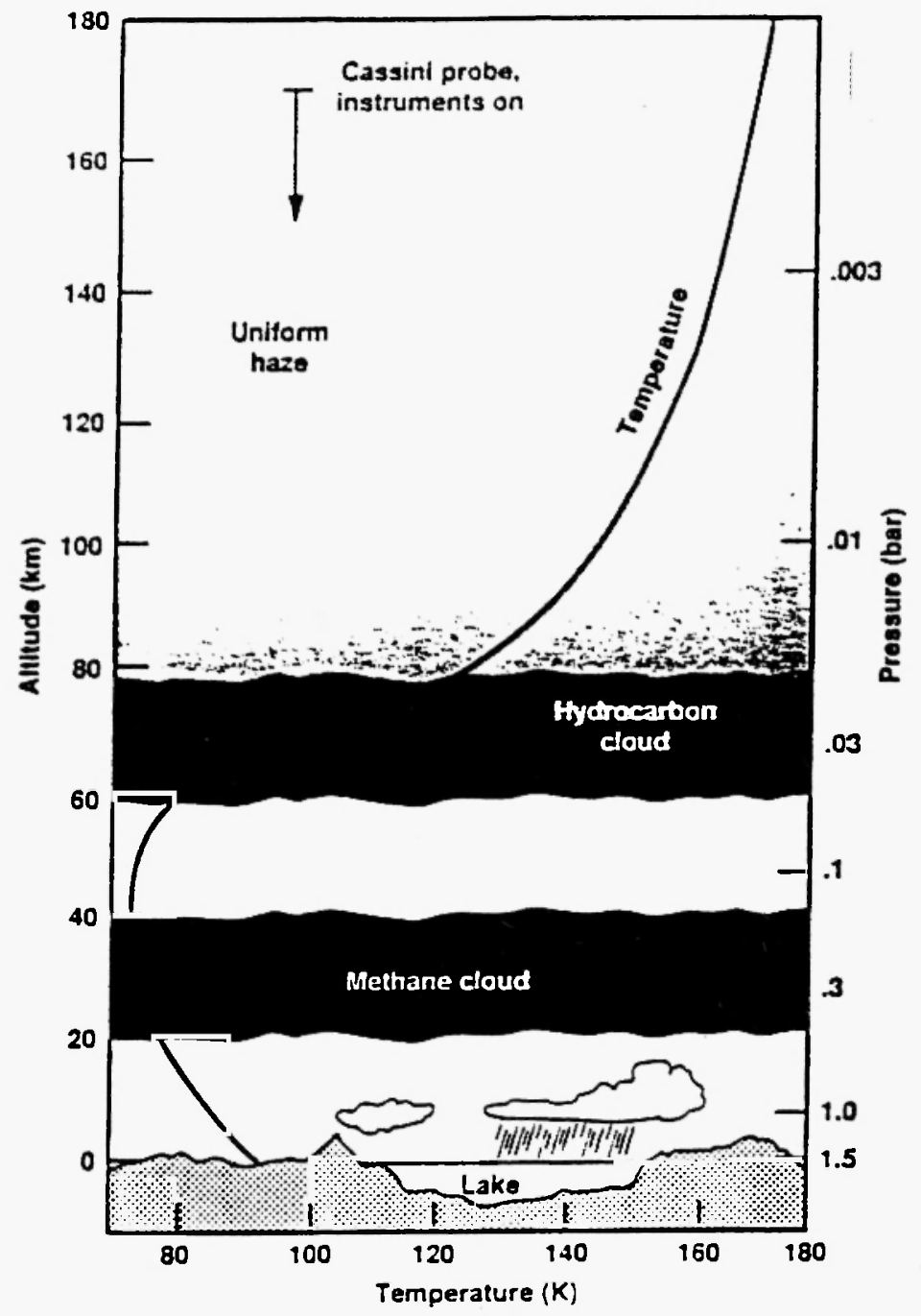

Fig. 2: shows the variability in pressure and temperature in relation to changes with altitude of Titan's atmosphere. Also, indicated in the figure is the altitude where the Cassini-Huygens probe instruments will become operational (courtesy of T. Scattergood, 1992, ref. 156/, reprinted with permission from NASA-Ames Research Center).

pathways involved in the formation of organic molecules in strato- and troposphere, and the nature and composition of Titan surface remains to be understood $/ 57 /$. 
In light of some of the above queries, an international collaboration of the National Aeronautics and Space Administration (NASA) with the European Space Agency (ESA) and the Italian Space Agency (ASI) resulted in the Cassini-Huygens mission (CHM) to Saturn. The CHM spacecraft was launched on October 15, 1997, and is anticipated to reach Saturn's orbit by the year 2004. The Cassini-Huygens spacecraft carries several analytical instruments intended to conduct a detailed study of Saturn's atmosphere, magnetosphere, the Saturnian rings and satellites, notably Titan. Attached to the Cassini spacecraft is an atmospheric probe, called the Huygens probe, to be released in December of 2004, for a three-hour detailed in-situ analysis of Titan's atmosphere. It is expected that results from the CHM may enhance our understanding of abiological synthesis of organic compounds on planets $158 /$.

The Huygens probe GC-MS comprises of a gas sampling system, five ion sources, a quadrupole mass analyzer and a secondary electron multiplier detection system /59/. The gas sampling system has three subsystems: direct atmospheric sampling, the $\mathrm{GC}$ and the aerosol collector pyrolyzer (ACP) interface. Direct atmospheric composition measurements will commence from an altitude of $170 \mathrm{~km}$ above the surface. The sample gases will be conducted through pressure reducing devices, passed through an enrichment and scrubber cell and introduced into the ion source of the mass spectrometer by means of fixed capillary leaks. By using a capillary array system (typically seven capillaries per leak with inside) instead of a single capillary, the likelihood of capillary blockage by small aerosol particles can be minimized /59/.

The samples will be collected between the atmosphere region of 176 and $60 \mathrm{Km}$ at three different altitudes and subsequently analyzed by passing through the GC columns. Because of insufficient time for real-time analysis of the gaseous constituents at the sampled altitude, the samples will be stored in sample containers and analyzed during the probe's descent into the lower part of the atmosphere.

The GC sub-system comprises of three parallel GC columns with distinct stationary phases. Two of the three GC columns are metal OTCs, which are for the first time deployed for space exploration. Of the two metal OTC columns, the inner wall of one of the columns contains a few microns of fused silica material, which is deactivated (a deactivation layer is formed) before depositing one (or more) micrometer of the desired polysiloxane stationary phase. The chromatographic performance of metal capillary columns has been found to be comparable to the fused silica capillary columns $/ 60,61 /$. 
The CHM GC-MS silica-coated steel column (10 m, length, $0.18 \mathrm{~mm}$ i.d., with $0.6 \mu \mathrm{m}$ film thickness, Restek Inc., Bellefonte, PA) contained a moderately polar phase $14 \%$ cyanopropylphenyl-86\% dimethyl polysiloxane stationary phase (CPPS-DMPS). The column is intended to provide separation of low molecular weight hydrocarbons and nitriles within a time interval of 10 minutes, at an isothermal temperature of $40^{\circ} \mathrm{C}$.

The second metal OTC column $(14 \mathrm{~m}, \mathrm{~L}, 0.18 \mathrm{~mm}$ i.d., $1 \mu \mathrm{m}$ film thickness) did not contain the fused silica lining within the inner wall of the column. Instead a specialized pretreatment of the metal OTC was carried out (at J\&W Scientific, Folsom, CA) before depositing the novel low temperature glassy carbon phase $/ 62 /$. Certain applications of the low temperature glassy carbon (LTGC) phase were also shown in high performance liquid chromatography and super critical chromatography /63/. The LTGC columns were developed for the first time to provide GC separation of ethane, ethene and ethine from a ninety nine percent nitrogen background, at an isothermal of $30^{\circ} \mathrm{C}$. The third column, a short silica-coated metal column $(2 \mathrm{~m}, \mathrm{~L}, 0.75 \mathrm{~mm}$, i.d.) was packed with a carbon molecular sieve (Carboxen 1000, Supelco Inc., Bellefonte, PA) to provide separation of trace quantities of $\mathrm{CO}$ and methane diluted in ninety nine percent $\mathrm{N}_{2}$. The columns were tightly coiled (approximately $179 \mathrm{~mm}$ diameter) with high temperature foil heaters, and each column was thermally isolated to enable efficient heating of the columns.

Prior to sample analysis, two of the three $\mathrm{GC}$ columns (the micropacked and the LTGC column) will be heated isothermally to $30^{\circ} \mathrm{C}$, whereas the third column, an OTC with the CPPS-DMPS phase will be heated to $40^{\circ} \mathrm{C}$. Hydrogen will be used as the carrier gas for the analysis of all the samples. During the introduction of the CHM aerosol pyrolysis sample, the temperature of the third column will be increased to $60^{\circ} \mathrm{C}$. A detailed description of the Huygens probe aerosol collector pyrolyzer and its interface to the GC-MS instrument has been discussed in an earlier publication $/ 64 /$.

\subsection{GC column stationary phase characterization}

The stationary phase of $\mathrm{GC}$ columns can be characterized by measuring the retention time data $/ 65 \%$. The composition of the stationary phase, temperature, GC column length, internal diameter of the columns, carrier gas type, and flow rate are some of the important variables that influence the retention time of the components $/ 66 /$. By measuring the retention time of the component and the gas hold up time at specified temperatures, the capacity 
factor ( $k$ ) of analytes can be determined. The " $k$ " can be equated to the thermodynamic coefficient $\left(\mathrm{K}_{\mathrm{d}}\right)$ by multiplying with the phase ratio of the column. Also, the relationship between the $K_{d}$ and the isothermal temperature can be expressed as:

$$
\log \overline{\boldsymbol{K}}_{\boldsymbol{d}}=\frac{A}{\overline{\boldsymbol{I}}_{\mathrm{c}}}+B
$$

where $T_{c}$ is the isothermal temperature in Kelvin, and $A$ and $B$ are constants.

An exponential relationship exists between $T_{c}$ and the solute retention time whereas the phase ratio, carrier gas velocity and the column length are linearily related to the solute retention time.

However, the $K_{d}$ values can be transformed to modeling number values, which is called $\log$ of $M$ (where $M$ is $\log K_{d}$ ). The empirical basis of modeling number was obtained by establishing a linear relationship between the $\log \mathrm{M}$ values and temperature expressed in celsius $/ 67 /$. The straight line plots obtained by this relationship are logarithmic values that are mapped in a linear domain and have the general expression:

$$
\log \left(\log \left(K_{d}\right)\right)=\log \left(b_{0}\right)-a_{0} T
$$

or letting $b_{1}=\log \left(b_{0}\right)$ and $a_{0}=a_{1}$, then

$$
\log (M)=b_{1}-a_{1} T
$$

$b_{1}$ is the intercept, $a_{1}$ is the slope of the line, and $T$ is the temperature (celsius).

Previously, several higher molecular weight normal and branched hydrocarbons were shown to retain a linear relationship between $\log \mathrm{M}$ and temperature $\left({ }^{\circ} \mathrm{C}\right)$ on various WCOT stationary phases $/ 67 /$. The variability of modeling number with temperature (in celsius) for three nitriles, analyzed on two different phases DMPS and CPPS-DMPPS is shown in Figure 3. On DMPS phase, acetonitrile exhibited two linear regions $\left(30-40\right.$ and $45-60^{\circ} \mathrm{C}$ ) with significant slope changes between 40 and $45^{\circ} \mathrm{C}$. At higher temperatures $\left(70^{\circ} \mathrm{C}\right.$, not shown in the figure), the relative retention time of acetonitrile on DMPS was significantly reduced, resulting in a sharp change in log M-temperature relationship. Both propane- and propenenitriles showed similar trends between the temperature intervals of 30 to $55^{\circ} \mathrm{C}$. Compared to 


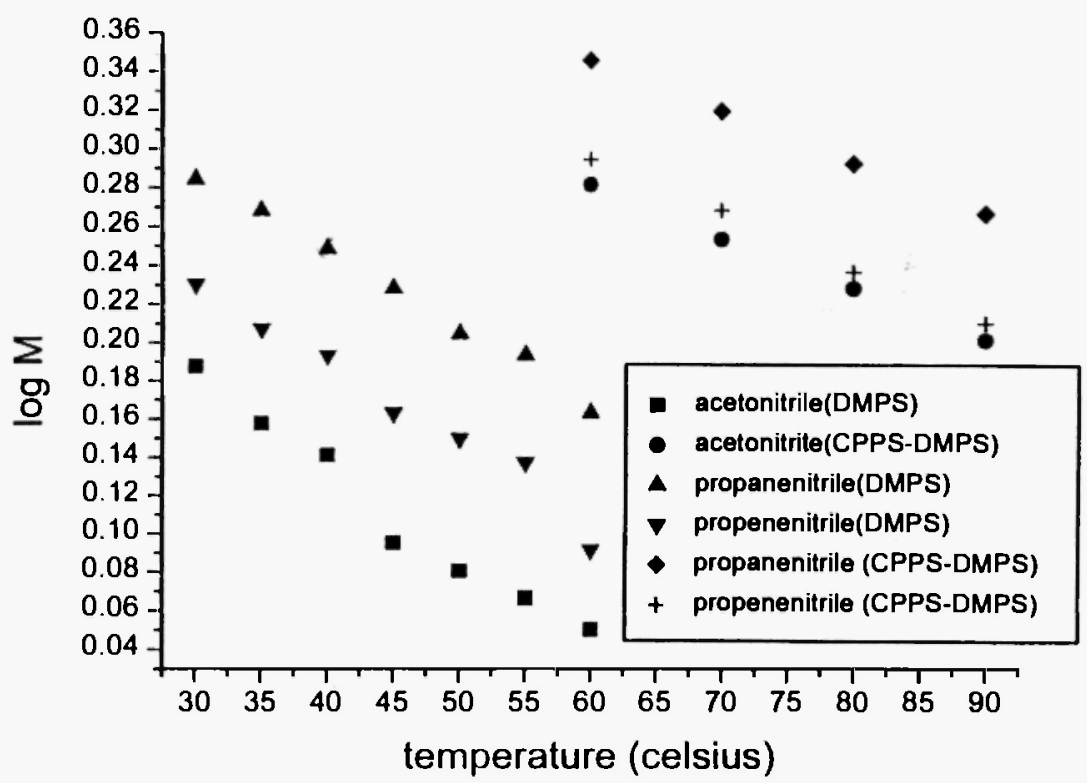

Fig. 3: provides a comparison of modeling number $(\log M)$ values for nitriles at different temperatures (in celsius) on $100 \%$ dimethyl polysiloxane (DMPS) and 14\% cyanopropylphenyl - $86 \%$ dimethyl polysiloxane (CPPS-DMPS) stationary phases.

the DMPS phase, the three nitriles on the CPPS-DMPS had higher log M values. The increased selectivity of the nitriles on the CPPS-DMPS becomes clearly evident when the $\log \mathrm{M}$ values for both the phases are compared at $60^{\circ} \mathrm{C}$ (Figure 3 ). Also, on the CPPS-DMPS phase, the nitriles exhibit a linear relationship ( $\log \mathrm{M}$ and temperature) even at a higher temperature interval (Figure 3).

Certain differences in the interaction of $\mathrm{C}_{4}$ hydrocarbons on the DMPS and CPPS-DMPS phase were also observed. For example, on the DMPS phase the retention time decreased as n-butane $>1,3$ butadiene $>1$-butene, whereas on the CPPS-DMPS it was 1,3 butadiene $>1$-butene $>n$-butane $/ 68 /$. On DMPS, all three components exhibited a linear decrease in $\log \mathrm{M}$ between the temperature interval of 40 to $60^{\circ} \mathrm{C}$ (Figure $4 \mathrm{a}$ ). The linear region for trans-butene on DMPS was in the temperature intervals of 40 and $60^{\circ} \mathrm{C}$ whereas for cis-2-butene, the linear region was between $50-60^{\circ} \mathrm{C}$. On CPPS-DMPS phase, $n$-butane and 1-butene, showed two linear regions (30-40 
Vol. XVIII, No. 3 Analytical Chemistry of Abiological and Biological Molecules by Gas Chromatography and Mass Spectrometry

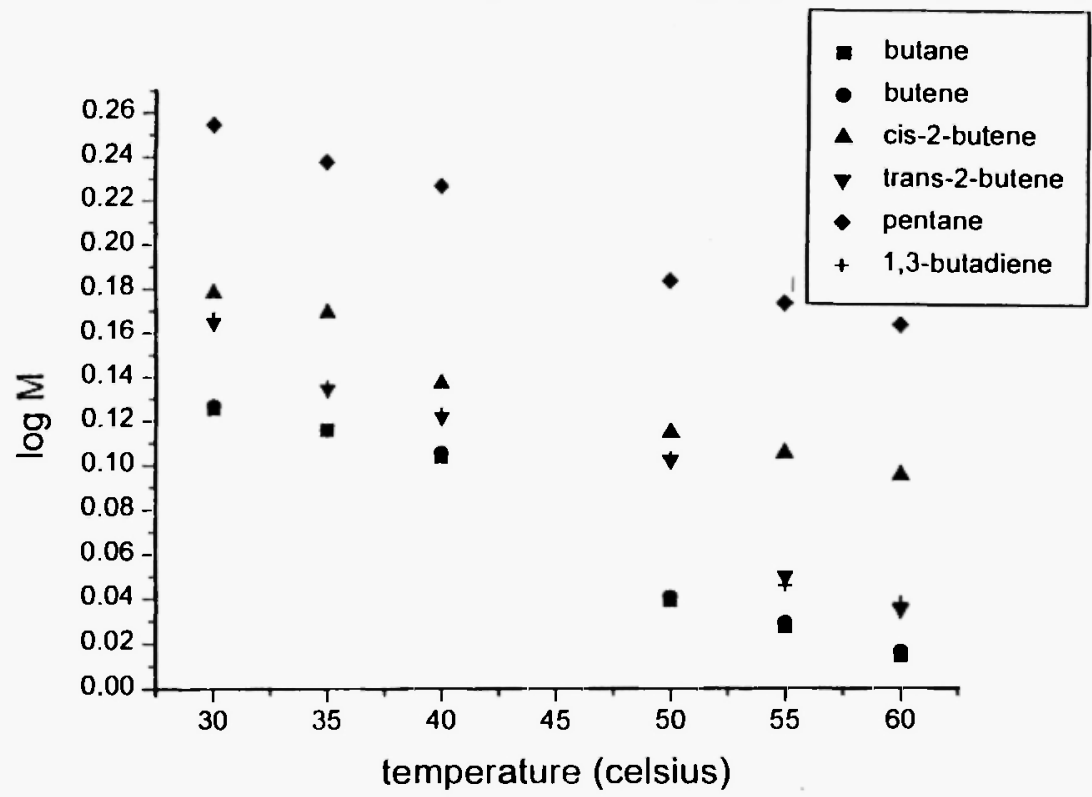

Fig. 4a: shows the variability in the modeling number for the $C_{4}$ and $C_{5}$ hydrocarbons on the DMPS phase over a temperature interval of 30-60 ${ }^{\circ} \mathrm{C}$.

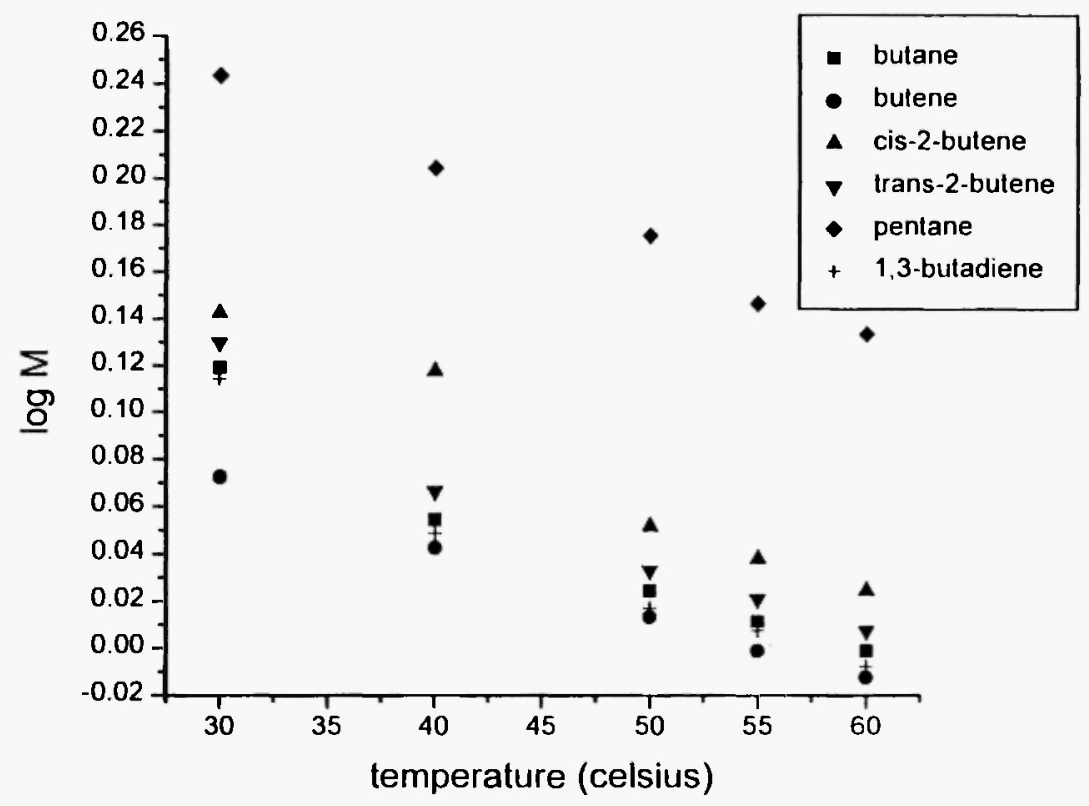

Fig. 4b: shows the variability in the modeling number for the $C_{4}$ and $C_{5}$ hydrocarbons on the CPPS-DMPS phase. 
and $50-60^{\circ} \mathrm{C}$ ) where the $\log \mathrm{M}$ value decreased with temperature. A significant enthalpy change for the molecules (partitioning between gas and the stationary phases) between the temperature interval 40 and $50^{\circ} \mathrm{C}$ may explain the observed $\log M$ changes for 1 -butene and $n$-butane on the CPPS-DMPS phase. On the CPPS-DMPS phase, 1,3 butadiene and trans-2-butene elute in proximity to each other, however, linear trends were observed for both molecules between the temperature interval of $35-50^{\circ} \mathrm{C}$ (Figure 4b).Both trans-2-butene and cis-2-butene interacted differently with DMPS and CPPS-DMPS stationary phases. Under identical isothermal conditions, the $\log M$ values for both cis-2-butene and trans-2-butene were lower on the CPPS-DMPS when compared with DMPS. Table 1 a and $1 b$ provide the linear equations that were generated by characterizing the interaction of $\mathrm{C}_{4}$ hydrocarbons, methyl-branched hydrocarbons, nitriles, and benzene, toluene and xylene (BTX) compounds on DMPS and CPPS-DMPS stationary phases /68/. The equations serve as a convenient means for calculating the retention time of components at any specified temperature, and facilitate in indexing the hydrocarbon isomers over certain temperature intervals. Navale et al. (1998) conducted a comprehensive study on the development and characterization of the three novel GC columns, which were integrated with the Huygen's probe miniaturized mass spectrometer. The work also experimentally demonstrated the separation of the important constituents of Titan's atmosphere by GC-MS analysis /68/. Following the above work, Sternberg et al. (1999) showed similar results by using thermal conductivity and flame ionization detection modes. However, the authors resolved the $C_{2}$ hydrocarbons, higher molecular weight hydrocarbons $\left(C_{4}\right.$ and above) and nitriles in the absence of $\mathrm{N}_{2}$, a predominant gas of Titan's atmosphere $/ 69 /$.

\section{ANALYTICAL CHEMISTRY OF ARCHAEAL GLYCEROL ETHER LIPIDS (GELS)}

Lipids, in general, are useful as chemical markers because individual groups of these compounds can indicate the presence and/or reflect upon the physiological condition of living organisms $/ 70 /$. Many of the structural features in lipid molecules, for example, the cyclic rings in steroids and terpenoids $/ 71 /$, and the ether bond of archaeal glycerol ether lipids, are known to resist microbial degradation $/ 72 /$. These molecules retain most of 


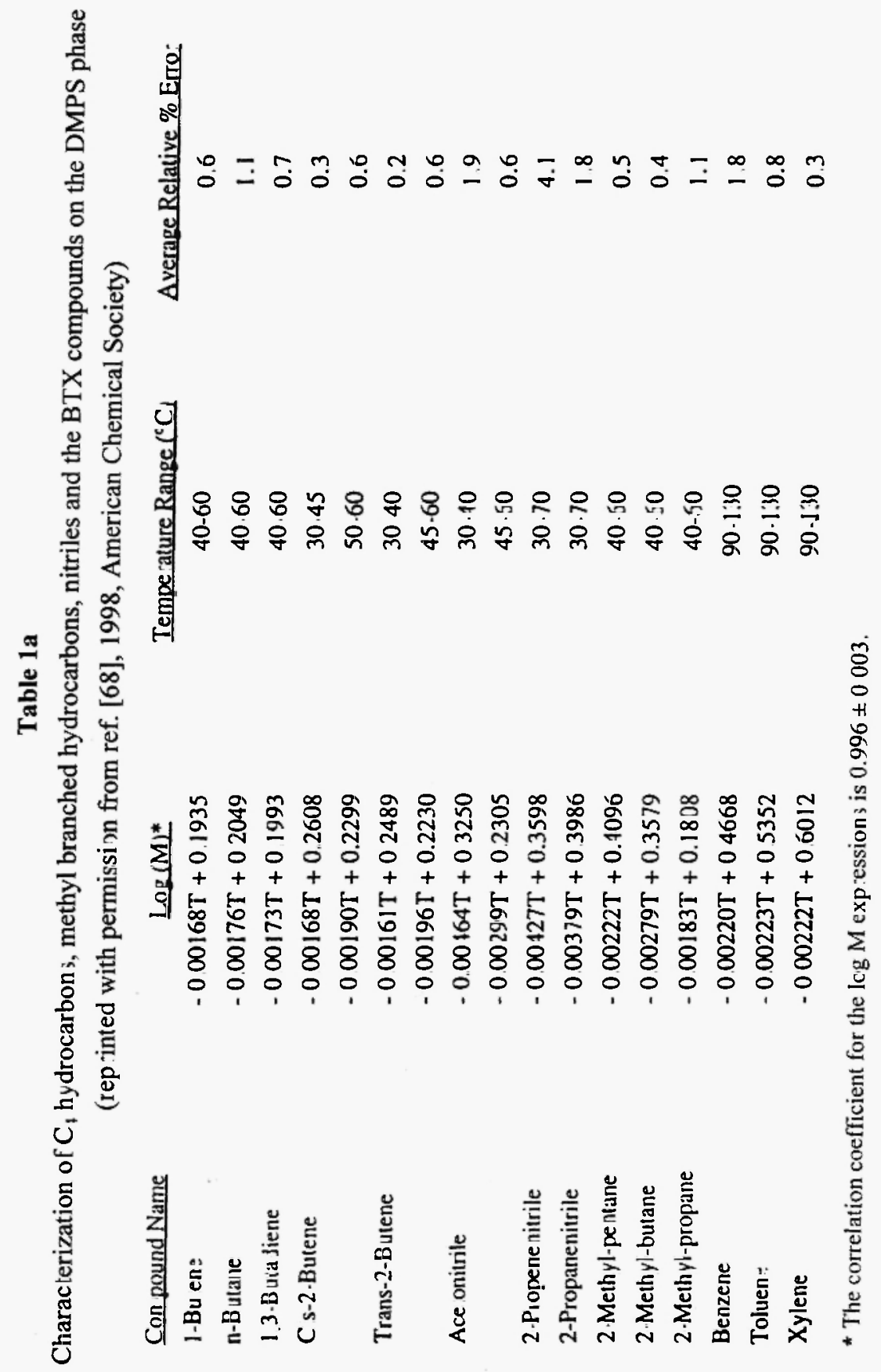




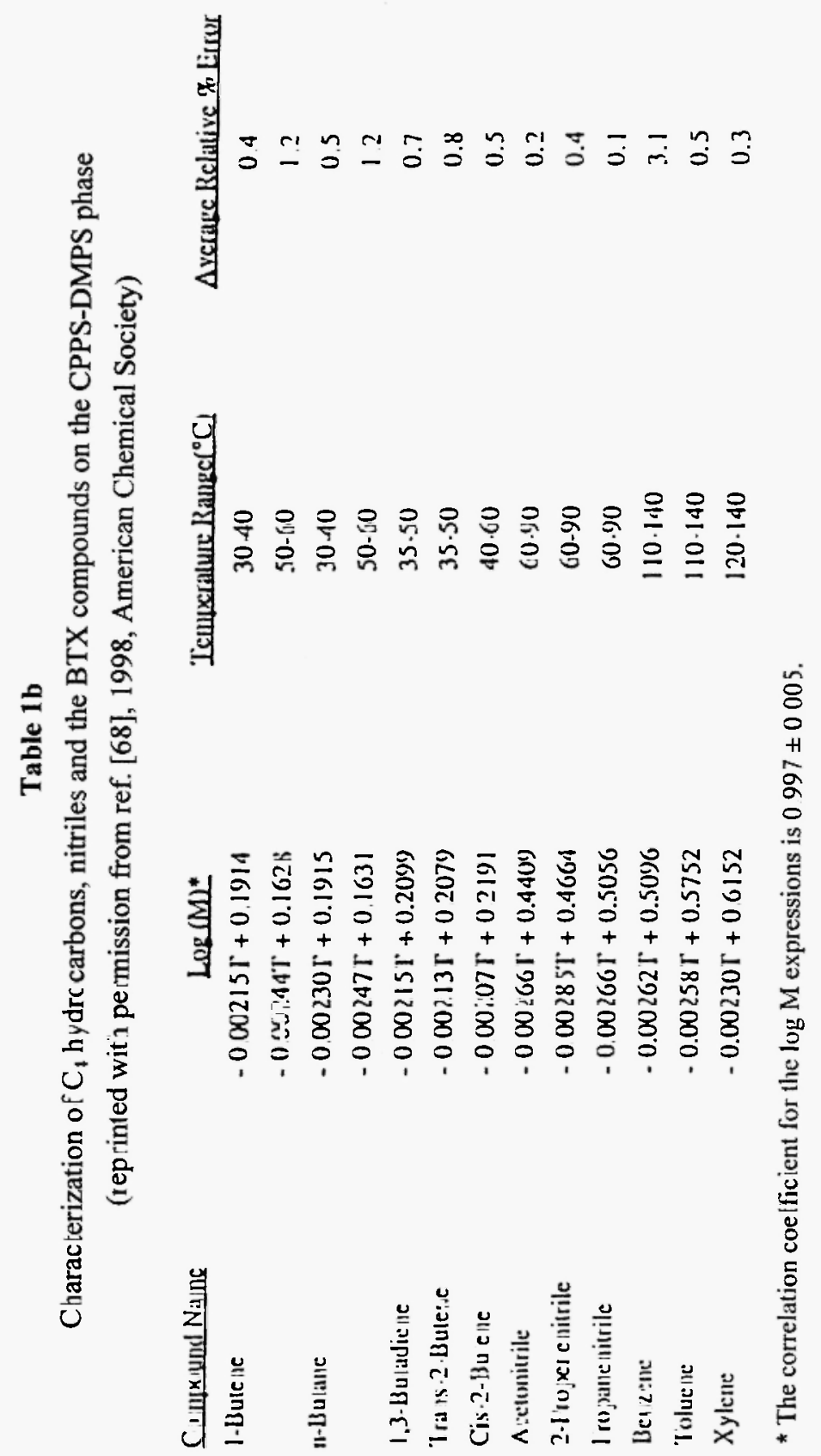


their structures and remain as biological markers in organic rich sediments, petroleum and in various other geological environments $/ 73,74 /$.

Archaea are microorganisms that possess several recognizable phenotypes (methanogens, halophiles, thermophiles, and thermoacidophiles), and have high degree of morphological variability and metabolic diversity /75/. These microbes are phylogenetically related to eukaryotes but inhabit a wide variety of ecological niches, such as the anoxic, hypersaline and hydrothermal environments $/ 76 /$. By molecular biological and biochemical methods, the archaea can be distinguished from eubacteria and eukaryotes by identifying (a) the $16 \mathrm{~S}$ ribosomal RNA sequence, (b) the glycosylated proteins of the cell wall, and (c) the cell membrane lipids that comprise of biphytanyl glycerol diether and its dimer biphytanyl diglycerol tetraethers $/ 77 /$. The biphytanyl glycerol ether lipids (GELs) are exclusively present in archaea, making them as excellent biological markers. The detection and identification of archaeal lipids and their decomposition products in a natural environment can serve as a good indicator of biological activity of such organisms.

Some of the representative structures of the archaeal GELs are shown in Figure 5. The most common $\mathrm{C}_{20}$ glycerol diethers (Fig 5a) consists of two phytanyl or similar side chains bound to the glycerol molecule by ether bonds 178/. The $\mathrm{C}_{20}$ phytanyl groups have an acyclic isoprenoid structure. This type of structure has been found in most archaea, and is the predominant ether-linked structure reported from extreme halophile. The $\mathrm{C}_{40}$ diglycerol tetraether consists of two glycerol diethers with the alkyl portions joined head-to-head at the 16, 16' positions (Fig. 5b). Such compounds were first found in extreme thermoacidophile of the Caldariella group, and subsequently in various methanogens $179 \%$. The $\mathrm{C}_{40}$ biphytanyl groups commonly contain two to four cyclopentanyl rings (Fig 5c and 5d). The glycerol calditol tetraethers are similar to the diglycerol tetraethers in their alkyl substituents; however, the alkyl moieties are ether-linked to one molecule of glycerol and one molecule of nonitol. These isoprenoid ethers have been isolated from Caldariella thermoacidophiles $/ 80$ /.

Several analytical methods have been used to differentiate archaea from eubacteria. Diffuse reflectance Fourier-transform IR spectroscopic measurements have shown that differentiation of these two types of organisms can be conducted by expressing the height of the ester peak as a percent of the methyl peak /81/. However, in the IR spectrum, several peaks at $1002 \mathrm{~cm}^{-1}$ could be related to the ether adsorbtion which made precise assignment of the peaks difficult. 
(a)

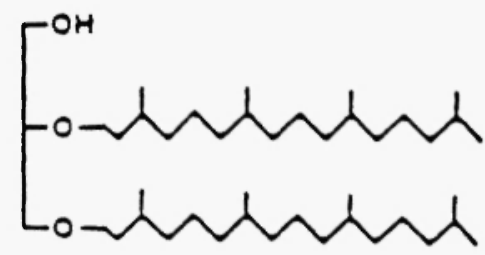

$\left(\mathrm{C}_{20}\right)$

(b)

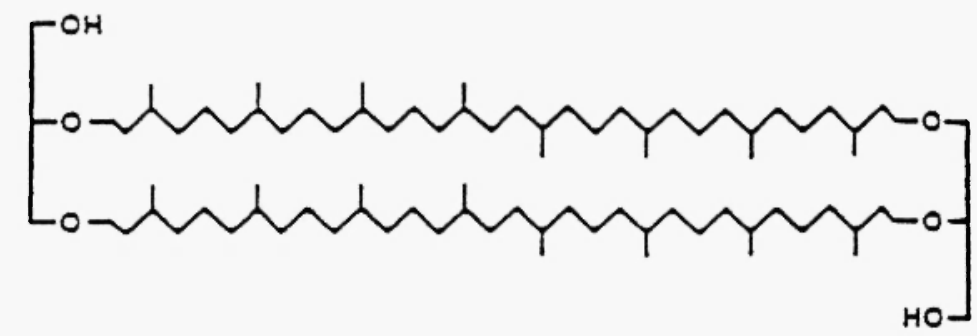

$\left(c_{40}-0\right)$

(c)

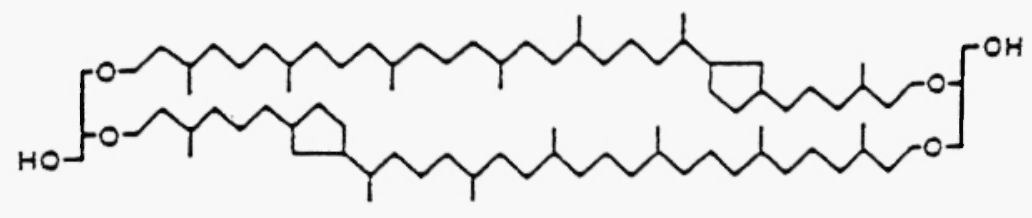
$\left(c_{40}-1\right)$

(d)

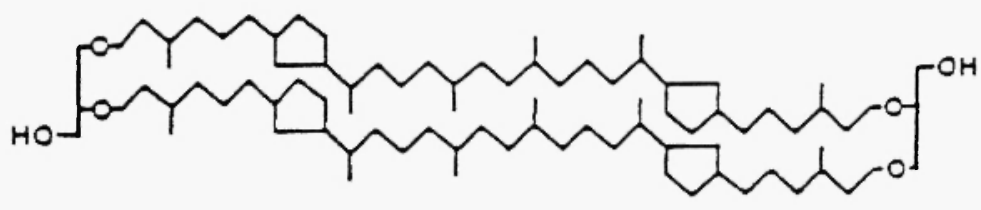

$$
\left(c_{40^{-2}}\right)
$$

Fig. 5: Schematic representation of archaeal glycerol ether lipids. (5a) shows two identical phytanyl $\left(-\mathrm{C}_{20} \mathrm{H}_{41}\right)$ side chains bound to the glycerol molecule by the ether bonds, $\left(5\right.$ b) shows the two $\left(-\mathrm{C}_{40} \mathrm{H}_{81}\right)$ side chains, diglycerol and tetra ether components, $(5 \mathrm{c})$ shows the presence of two cyclopentanyl rings in each chain of the structure shown in 5b, and (5d) indicates the four cyclopentanyl rings. (reprinted from Pauly \& Van Vleet, 1986, ref $178 /$ with kind permission from Elsevier Science). 
Detection of the isoprenoid hydrocarbons produced from chemical degradation of archaeal GELs by the GC-MS method has a sensitivity of 5 to 10 nanograms $/ 82 /$. The multi-step sample preparation required prior to GC-MS analysis may lead to sample contamination and quantitative uncertainty during trace analysis work. Recent improvements in sample preparation involving purification of the crude lipid extract into glycolipids, phospholipids, and polar lipids followed by supercritical chromatography have shown a three fold increase in the information content of the lipids /83/. Similarly, liquid chromatographic methods have shown to be sensitive for detection of nanogram levels of glycerol diethers and tetraethers /84/.

The high performance liquid chromatographic (HPLC) method is another sensitive method for detecting trace quantities of GELs from various environmental substrates. Direct mass spectrometric analysis by Fast Atom Bombardment (FAB)-MS of polar ether lipids from several Halobacterium species was attempted earlier $/ 85 /$. The FAB-MS analysis of the total lipid fraction from different strains of Methanospirilium hungatei showed a single molecular ion $/ 86 \%$. It is likely that the combined method of HPLC and MS system may be able to separate and identify different species of archaea.

Several different strains of microorganisms have been analyzed by combining pyrolysis technique with GC-MS $/ 87 \%$. Pyrolysis methods have also been employed to simulate the chemical changes occurring in sediments at shallow subsurface (early diagenesis), and at greater sediment depths (catagenetic changes) where the thermal effects predominate $/ 88 \%$. The pyrolysis method has also been extended to determine the source of disseminated organic matter (kerogen) in sediments $189 \%$.

Broadly, two types of pyrolysis methods are conducted, the Flash pyrolysis (FP) and Hydrous pyrolysis (HP). The FP method involves the rapid heating of samples in an anhydrous environment, where the temperature increase is typically in the range of $300^{\circ} \mathrm{C} / \mathrm{sec}$. The pyrolysis time interval, however, is a few seconds and less. The HP mode is conducted in the presence of water and the temperature increase in a HP experiment is gradual. The typical $\mathrm{HP}$ experiments maintain a final temperature of $330^{\circ} \mathrm{C}$, for a period of three days. The use of lower temperatures and longer time intervals seems to be a better approximation of the processes operating in the natural environment. The HP method has been used in the laboratory for many applications, e.g., for simulating oil generation processes $190 /$, releasing organic compounds from coal and black shales $191 /$, for analyzing polymers 192/, and for formation of PAHs from steroids and terpenoids 193/. The 
following section examines the effect of thermal stress on GELs by pyrolysis GC-MS methods.

\subsection{Anhydrous Pyrolysis of GELs}

FP experiments on the GELs were carried out directly by interfacing a commercial pyrolyzer with a GC and a GC-MS. Many different types of pyrolyzer configurations are possible, and general considerations regarding the interface of such units to analytical instruments have been discussed previously 194/. The pyrolyzer was calibrated by using the molecular thermometer model method 195/. This concept relates the pyrolysis set temperature (PST) of the probe to the actual temperature that the sample experiences during pyrolysis, which is referred as the pyrolysis equivalent temperature (PET). The PET can be determined by pyrolyzing a co-polymer "Kraton 1701" (Chemical Data Systems, Oxford, PA) between a temperature interval of 500 to $850^{\circ} \mathrm{C}$. The Kraton pyrolysis products isoprene and dipentene are analyzed by $\mathrm{GC}$, and the $\mathrm{R}$ value (ratio of isoprene and dipentene GC peak area) is calculated between the temperature interval of 500 to $850^{\circ} \mathrm{C}$. The relationship obtained for the $R$ values at various PST temperatures is correlated to the values determined by the temperature calibrated probe. This procedure accounts for the errors between the PST and the actual temperature experienced by the sample and can help in unifying the pyrolysis data for different instrument design 195/. For simplicity in discussion the temperature stated in the following paragraphs will be the PST values.

Dimyristyl glycerol ether lipid (DMGEL, $\mathrm{C}_{31} \mathrm{H}_{64} \mathrm{O}_{3}$ ), dipalmityl glycerol ether lipid (DPGEL, $\mathrm{C}_{35} \mathrm{H}_{72} \mathrm{O}_{3}$ ), and distearyl glycerol ether lipid (DSGEL, $\mathrm{C}_{39} \mathrm{H}_{80} \mathrm{O}_{3}$ ) are model compounds that were used for studying the chemical transformation of GELs to hydrocarbons. The non-bacterial GELs have a similarity to archaeal GELs, which contains the hydrocarbon moiety attached to the glycerol molecule via ether bonds. These molecules are reliable model compounds for studying the effect of induced thermal stress on the $\mathrm{C}-\mathrm{O}-\mathrm{C}$ linkage.

At higher temperatures $\left(900^{\circ} \mathrm{C}\right)$, pyrolysis of DM, DP, and DSGEL produced significant amounts of volatile hydrocarbons $\left(C_{1}\right.$ to $\left.C_{7}\right)$ and a series of mono-olefins $\left(\mathrm{C}_{9: 1}-\mathrm{C}_{18: 1}\right)$. Lowering the temperature to $400^{\circ} \mathrm{C}$ showed no pyrolysis products for DP and DSGEL. At $400^{\circ} \mathrm{C}$, the DMGEL pyrolysis products were $C_{14: 1}, C_{14}, C_{13}, C_{13: 1}$, and $C_{12: 1}$ hydrocarbons. Incipient traces of 
$C_{1}$ to $C_{7}$ hydrocarbons were also observed in the pyrograms. The mono-olefins ranging from $\mathrm{C}_{9}$ to $\mathrm{C}_{11}$ were detected as trace constituents when pyrolysis temperatures for DMGEL was increased to $500^{\circ} \mathrm{C}$. At $600^{\circ} \mathrm{C}$, the pyrolysis products of DMGEL showed a complete series of volatile components ranging from $C_{1}$ to $C_{7}$, and mono-olefins $\left(C_{9: 1}\right.$ to $\left.C_{11: 1}\right)$. The relative peak area of $C_{14: 1}$ decreased with significant increase in the volatile hydrocarbon $\left(\mathrm{C}_{1}\right.$ to $\left.\mathrm{C}_{8}\right)$ content.

Compared to the DMGEL, the minimum temperature required to detect $\mathrm{C}_{12}$ to $\mathrm{C}_{16}$ hydrocarbons from DPGEL was $500^{\circ} \mathrm{C}$. Significant amounts of volatile components and mono-olefins $\left(\mathrm{C}_{9: 1}\right.$ to $\left.\mathrm{C}_{12: 1}\right)$ were detected at $900^{\circ} \mathrm{C}$. The ratio of $\mathrm{C}_{15} \mathrm{H}_{32} / \mathrm{C}_{15} \mathrm{H}_{30}$ was found to be less than 1 at $900^{\circ} \mathrm{C}$, which increased to 3.8 when the temperature was decreased to $500^{\circ} \mathrm{C}$. At lower temperatures the content of volatile components, and the $\mathrm{C}_{16} \mathrm{H}_{32}$ fragment was less, and it was possible to identify the $\mathrm{C}_{16} \mathrm{H}_{34}$ component. The relative percentage of $\mathrm{C}_{16} \mathrm{H}_{34}$ seemed to decrease when the temperature was increased to $900^{\circ} \mathrm{C}$.

No pyrolysis products were observed for DSGEL at $500^{\circ} \mathrm{C}$. By increasing the temperature to $600^{\circ} \mathrm{C}$, a series of DSGEL hydrocarbon products ranging from $C_{1}$ to $C_{18}$ were observed. Trace amounts of volatile components $\left(C_{1}\right.$ to $\mathrm{C}_{7}$ ) were detected at $600^{\circ} \mathrm{C}$ and the percentage of volatile content increased significantly at $800^{\circ} \mathrm{C}$. Table 2 provides a semi-quantitative analysis of the hydrocarbons produced by pyrolysis of the DM, DP, and DSGEL. All three molecules (DM, DP, and DSGEL) show an increase in volatile hydrocarbon content at elevated temperatures, which correlates with the decrease in relative percentage of the $\mathrm{GC}$ peak area of the primary hydrocarbon component, $\mathrm{C}_{14: 1}, \mathrm{C}_{16: 1}$, and $\mathrm{C}_{18: 1}$ (normal unsaturated hydrocarbons). The corresponding increases in the volatile component for DS, DP and DMGEL were observed at 800,700 , and $600^{\circ} \mathrm{C}$, respectively.

The ratios of the doublets, $n-C_{13} / n-C_{13: 1}$ for DMGEL, $n-C_{15} / n-C_{15: 1}$ for DPGEL and $n-C_{17} / n-C_{17: 1}$ for DSGEL varied with pyrolysis temperature. The $n-C_{15} / n-C_{15: 1}$ to $n-C_{17} / n-C_{17: 1}$ ratio were less than 1 at $900^{\circ} \mathrm{C}$. Lowering the temperature to $600^{\circ} \mathrm{C}$ resulted in an increase of $n-C_{15}$ and $n-C_{17}$ fragments (the ratio of $n-C_{15} / n-C_{15: 1}$ and $n-C_{17} / n-C_{17: 1}$ was greater than 1). The results indicate that at higher pyrolysis temperatures dehydrogenation reactions dominate, which promote the formation of mono-olefins 196/. There are, however, differences in the temperature for the formation of primary hydrocarbon fragments which is $400^{\circ} \mathrm{C}, 500^{\circ} \mathrm{C}, 600^{\circ} \mathrm{C}$ for DMGEL, DPGEL, and DSGEL, respectively. The results indicate that for GELs with longer 


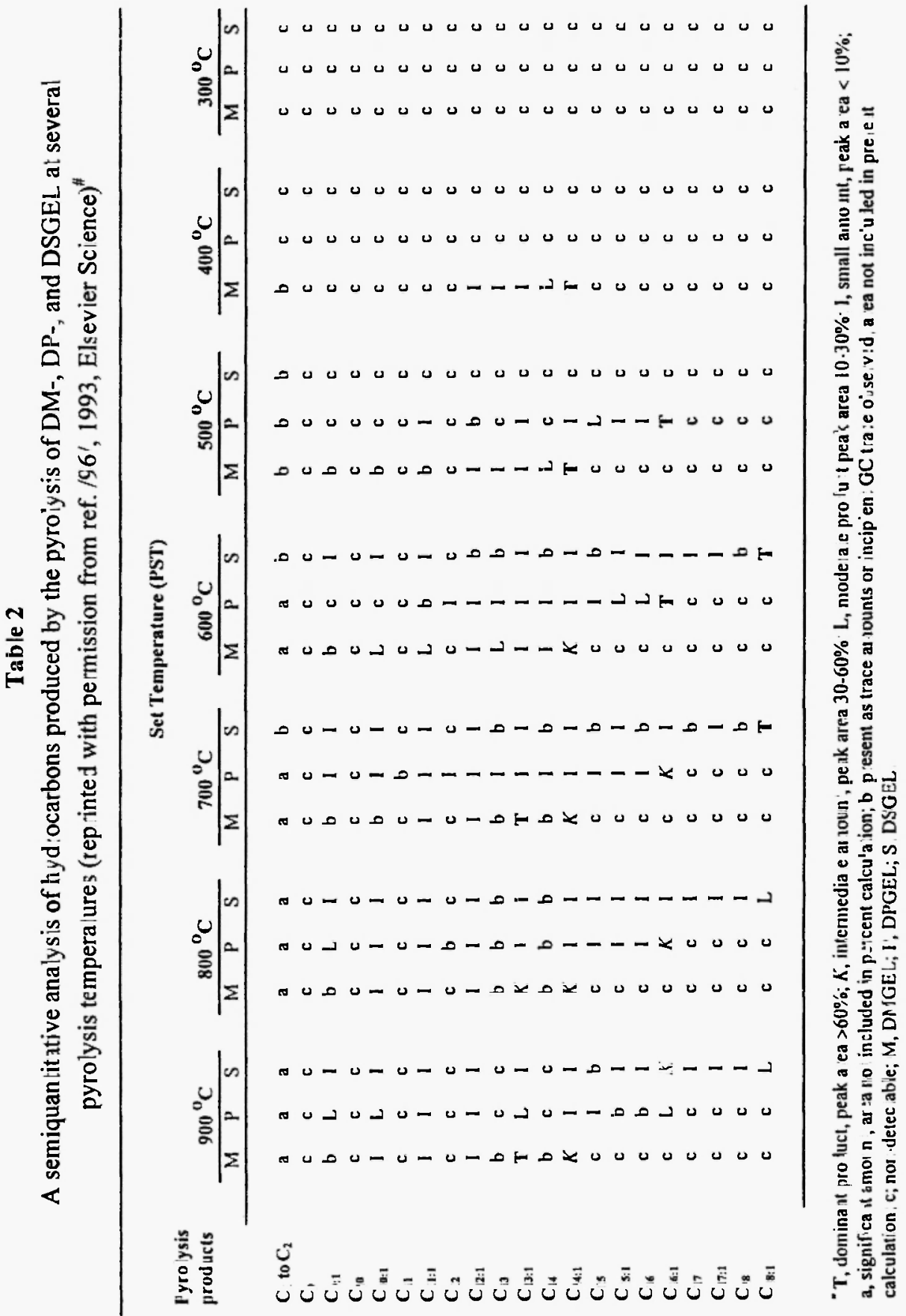


hydrocarbon side chains, higher pyrolysis temperatures are required for the formation of primary degradation products. For example, compared to DPGEL, an additional $45^{\circ} \mathrm{C}$ (PET) is needed to form the primary hydrocarbon fragment from DSGEL.

Previous studies on pyrolysis of alkanes have shown that at higher temperatures, mono-olefins are the predominant products, and the largest mono-olefin fragment has one less carbon number than the carbon number of the precursor alkane $197 /$. By contrast the largest mono-olefin produced from GEL has a carbon number equal to the number of carbons present in the hydrocarbon chain, i.e., $\mathrm{C}_{14: 1}, \mathrm{C}_{16: 1,}, \mathrm{C}_{18: 1}$, for DMGEL, DPGEL, and DSGEL, respectively.

In addition to the series of hydrocarbons produced during FP of DM, DP and DSGEL, alcohols were also identified from all the GELs. Figure 6a is the FP profile of DSGEL at $900^{\circ} \mathrm{C}$, in which alcohols, $\mathrm{C}_{18} \mathrm{H}_{37} \mathrm{OH}$ and $\mathrm{C}_{18} \mathrm{H}_{36} \mathrm{O}$, and a series of hydrocarbons ranging from $\mathrm{C}_{1}$ to $\mathrm{C}_{18}$ were seen. At a lower temperature of $300^{\circ} \mathrm{C}$, only the alcohols were observed (Figure 6b). A summary of the relative percentages of individual breakdown products of DSGEL produced as a result of pyrolysis at different temperatures has been provided earlier $198 /$. The Pyr-GC-MS of DPGEL at $900^{\circ} \mathrm{C}$ also verified the presence of $\mathrm{C}_{16} \mathrm{H}_{32} \mathrm{OH}$ and $\mathrm{C}_{16} \mathrm{H}_{31} \mathrm{O}$. The ions $\mathrm{m} / \mathrm{z} 224$ and $\mathrm{m} / \mathrm{z} 222$ resulting from the loss of a water molecule (M-18) from the molecular ions $\left(\mathrm{M}^{+} 242\right.$ and $\mathrm{M}^{+} 240$ ), were assigned to the normal saturated $\left(\mathrm{C}_{16}\right)$ and unsaturated $\left(\mathrm{C}_{16: 1}\right)$ alcohols, respectively. The presence of $\mathrm{C}_{16}$ hydrocarbon was confirmed by identifying the molecular ion $\mathrm{M}^{+} 224$ and the primary fragment ion $\mathrm{m} / \mathrm{z} 41$.

The FP of the three archaeal GELs, M. barkeri, Haloalkaphile sp and S. sulfotaricus also produced a series of FP pyrolysis products. At FP temperature of $300^{\circ} \mathrm{C}$, significant $(>95 \%)$ of the archaeal GEL from $\mathrm{M}$. barkeri remained intact. Both phytanol and phytene were produced. With increase in pyrolysis temperatures from 300 to $900^{\circ} \mathrm{C}$, alcohols, aldehydes, and a series of alkenes and volatile components were detected $/ 99 /$. At $900^{\circ} \mathrm{C}$, the relative percentage of volatile components increased significantly and was nearly equal to the unpyrolyzed GEL. The Haloalkaphile FP products included the phytanyl $\left(\mathrm{C}_{20}\right)$ and sestertepanyl $\left(\mathrm{C}_{25}\right)$ alcohols, alkenes and aldehydes. The FP profile of $\mathrm{S}$. sulfotaricus showed a complex suite of pyrolysis products, which included $\mathrm{C}_{25}, \mathrm{C}_{30}$ and $\mathrm{C}_{35}$ isoprenoid alkenes. The $\mathrm{C}_{40}$ alcohols, ketones and alkenes were not identified in the FP products of 


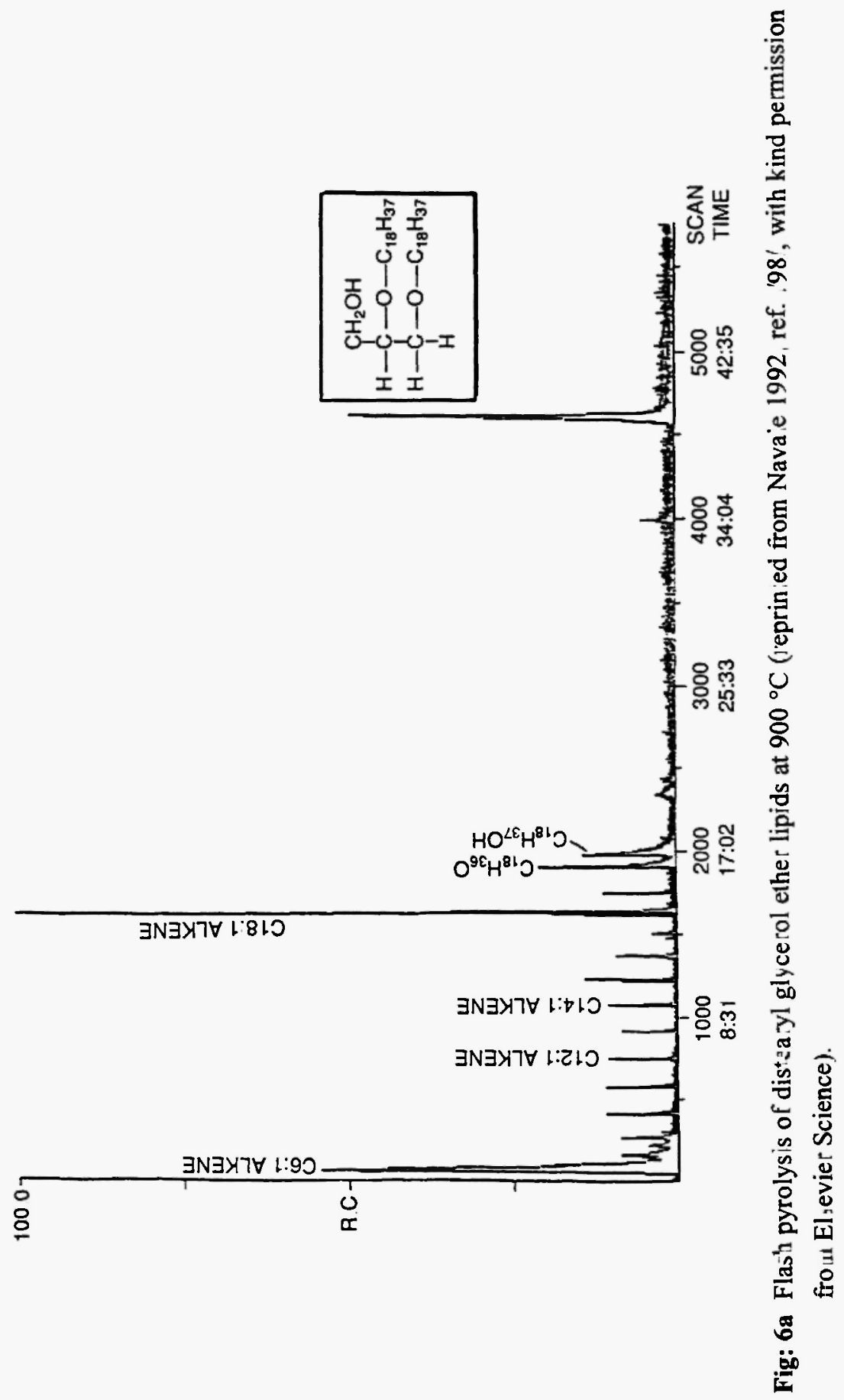




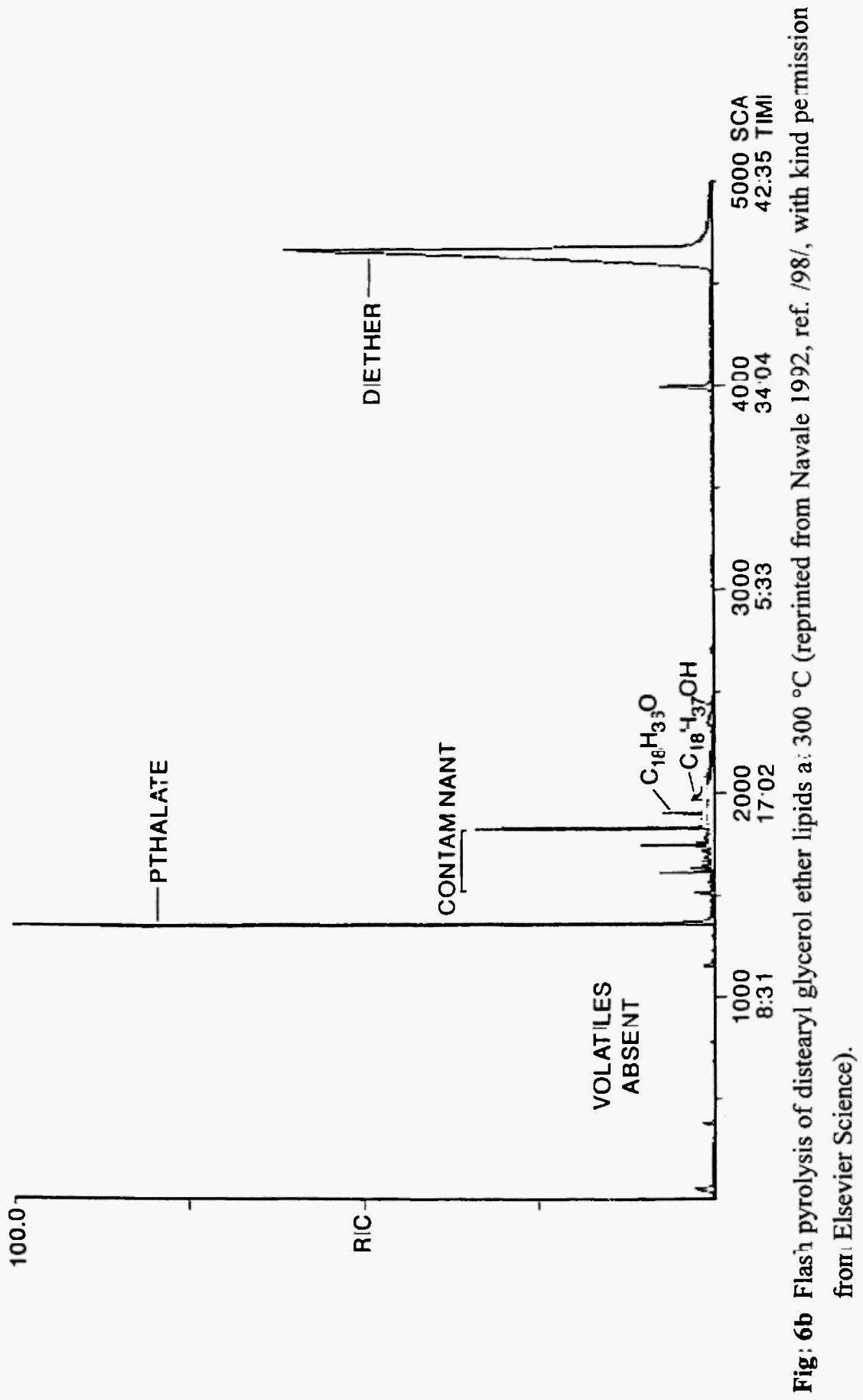


the S. sulfotaricus, probably due to the limitations in the GC column conditions used for the analysis $/ 99 /$.

Overall the FP of the archaeal GELs data clearly support the author's earlier work that had identified alcohols as the intermediate products formed during the transformation of GELs to hydrocarbons. The formation of $\mathrm{C}_{18} \mathrm{H}_{36} \mathrm{O}$ and $\mathrm{C}_{18} \mathrm{H}_{37} \mathrm{OH}$ from DSGEL at $300^{\circ} \mathrm{C}$ shows that the ether bonds of the DSGEL molecule is susceptible to thermal stress at the above stated FP temperature value. However, the $\mathrm{C}-\mathrm{C}$ bond scission in the DSGEL hydrocarbon chain required temperatures of $600^{\circ} \mathrm{C}$. The pathway of GEL decomposition involves dehydration of the alcohols, which is followed by hydrocarbon formation. The dehydrogenation reactions of saturated hydrocarbons and progressive loss of $\mathrm{CH}_{2}$ units results in the formation of a series of mono-olefins and volatile hydrocarbons. At significantly higher pyrolysis temperatures, hydrocarbon free radicals may be formed, which may result in the formation of lower molecular weight hydrocarbons. The free radical pathway for hydrocarbon formation from polyethylene has been proposed previously $/ 100 /$.

The decrease in the ratio of normal saturated to unsaturated hydrocarbons $(<1)$, shows that dehydrogenation reactions are promoted at higher pyrolysis temperatures. The studies indicate that with the FP time intervals (few seconds and less), the minimum temperature required to initiate $\mathrm{C}-\mathrm{C}$ bond cleavage depends on the length of the hydrocarbon side chains of the GEL molecules (i.e., shorter the GEL hydrocarbon chain, lower is the pyrolysis temperature for the initiation for the $\mathrm{C}-\mathrm{C}$ bond scission).

\subsection{Hydrous pyrolysis of GELs}

Earlier HP work had reported the formation of a series of acyclic hydrocarbons from methanogen cells /101/. Recent investigations by the author conducted initially in the absence of clay minerals showed the formation of both polar and non-polar pyrolysis products 198/. The HP pyrolysis products of the methanogen GEL identified (for the first time) the presence of dihydrophytol $\left(\mathrm{C}_{20} \mathrm{H}_{41} \mathrm{OH}\right)$ with hydrocarbons (phytene and pristane) (Figure 7a). In a similar experiment, montmorillonite (a clay mineral) was added to the methanogen extract and pyrolysis was conducted under identical conditions. Dihydrophytol, phytene and phytane were evident as the primary products. An isoprenoid aldehyde, 3,7,11,15-tetramethylhexadecan-1-al was also identified $/ 102 /$. It suggests that during the HP of 
GEL, aldehyde formation could have occurred by the reduction of dihydrophytol. Under similar HP conditions, the reduction of n-octadecanol to n-octadecanal has also been previously reported $/ 103 /$.

Both $\mathrm{C}_{20}$ and $\mathrm{C}_{20}$ diether glycerol $\left(\mathrm{C}_{43} \mathrm{H}_{88} \mathrm{O}_{3}\right)$ and $\mathrm{C}_{20}$ and $\mathrm{C}_{25}$ diether glycerol $\left(\mathrm{C}_{48} \mathrm{H}_{98} \mathrm{O}_{3}\right)$ lipids may be present in the haloalkaphile species of archaea. Hence, HP of haloalkaphile GEL showed the formation of a series of products: 3,7,11,15-pentamethyleicosan-I-ol $\left(\mathrm{C}_{25} \mathrm{H}_{51} \mathrm{OH}\right), 3,7,11,15,19$ - pentamethyleicosan-1-al $\left(\mathrm{C}_{25} \mathrm{H}_{50} \mathrm{O}\right), 2,6,10,16,18$-pentamethyleicosane $\left(\mathrm{C}_{25} \mathrm{H}_{50}\right)$, 3,7,11,15-tetramethylhexadecan-1-ol $\quad\left(\mathrm{C}_{20} \mathrm{H}_{41} \mathrm{OH}\right), \quad 3,711,15$-tetramethyl hexadecan-1-al $\left(\mathrm{C}_{20} \mathrm{H}_{40} \mathrm{O}\right)$, and 3,7,11,15-tetramethylhexadec-1-ene $\left(\mathrm{C}_{20} \mathrm{H}_{40}\right)$ 198\%. The findings were consistent with the pyrolysis products of the methanogen, and further confirmed the formation of isoprenoid alcohols as one of the important pyrolysis products.

HP of methanogen GELs conducted at $150^{\circ} \mathrm{C}$ for a period of seventy two hours resulted in the formation of isoprenoid alcohol and isomers of monoalkyl glycerol ether lipids (Figure 7b) /102/. No hydrocarbons were detected at that temperature. The HP findings were also consistent with the FP results that verified alcohols formation, prior to hydrocarbon generation. Increasing the time interval from three to sixty days for the $\mathrm{HP}$ at $150^{\circ} \mathrm{C}$ showed trace amount of hydrocarbon formation 199/. However, the relative percentage of hydrocarbons formed even after a sixty-day period at $150^{\circ} \mathrm{C}$ was less than one tenth of the alcohol amount produced during these experiments.

At $\mathrm{HP} 330^{\circ} \mathrm{C}$, the hydrocarbons seem to account for nearly $18 \%$ of the HP products. The other components namely, the alkanols, aldehydes, alknones, alkanoic acids were found to be less than $0.1 \%$. The relative percentage of alcohols detected at HP $330^{\circ} \mathrm{C}$ was less than the products produced at HP $150^{\circ} \mathrm{C} / 99 /$. The study concurred with the FP results that indicated the presence of significant portion of unpyrolyzed GEL component at lower temperatures. No GEL pyrolysis products were detected at a pyrolysis temperature of $100^{\circ} \mathrm{C}$ or lower, even with time duration of sixty days. These observations seem to suggest that GELs are reliable biological markers, and alcohols, monoalkylglycerol ether lipids and hydrocarbons are their likely decomposition products.

The C-O-C linkage of the GEL molecule is susceptible to thermal stress at $150^{\circ} \mathrm{C}$ that results in the formation of 3,7,11,15-tetramethylhexadecan-1-ol and monoalkyl glycerol ether isomers 1,3-propanediol-2-[(3,7, 11,15-tetramethyl hexadecyl)oxy] and 1,2-propanediol-3-[(3,7,11,15-tetramethyl hexa- 


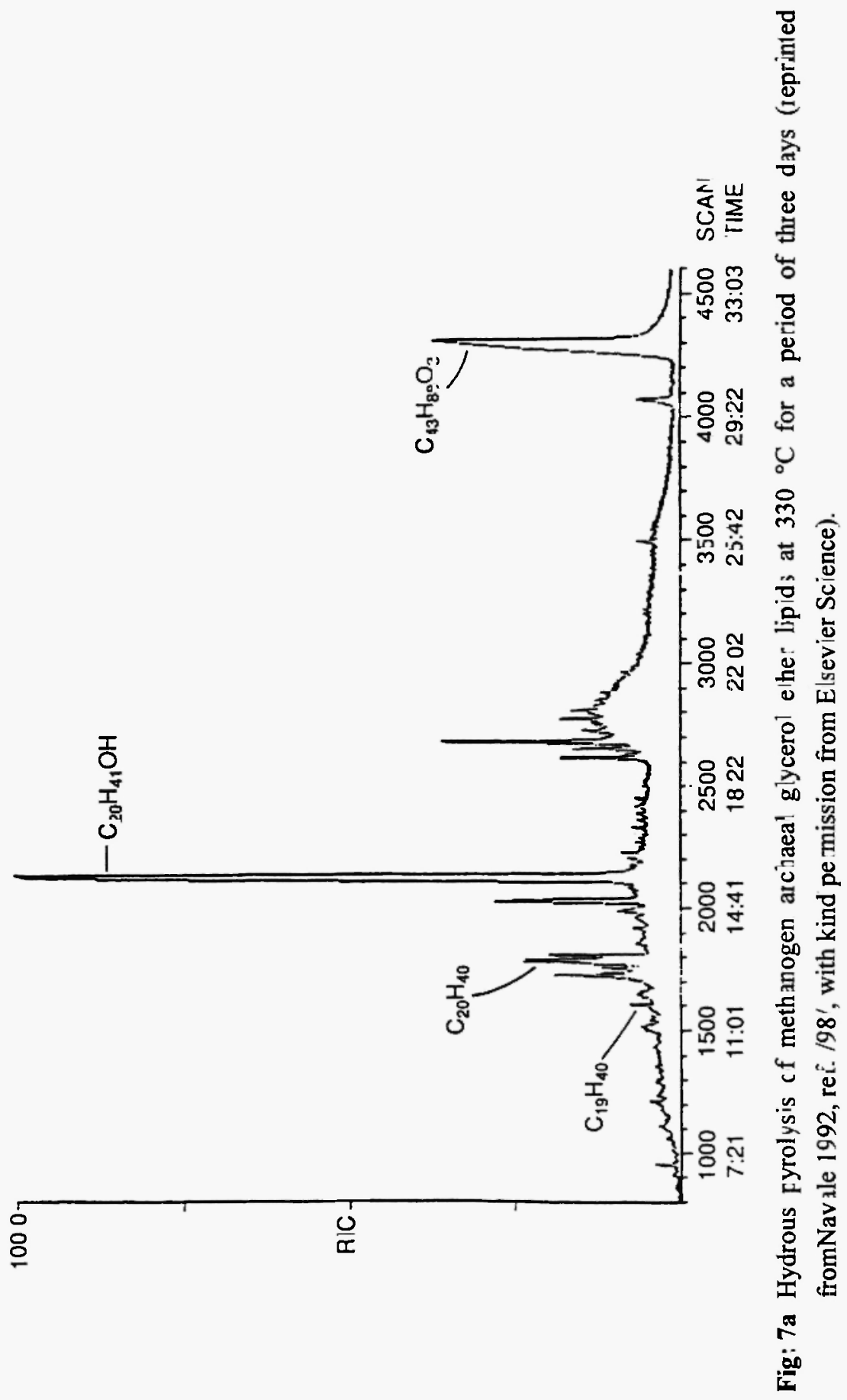


Vol. XVIII, No. 3 Analytical Chemistry of Abiological and Biological Molecules by Gas Chromatography and Mass Spectrometry

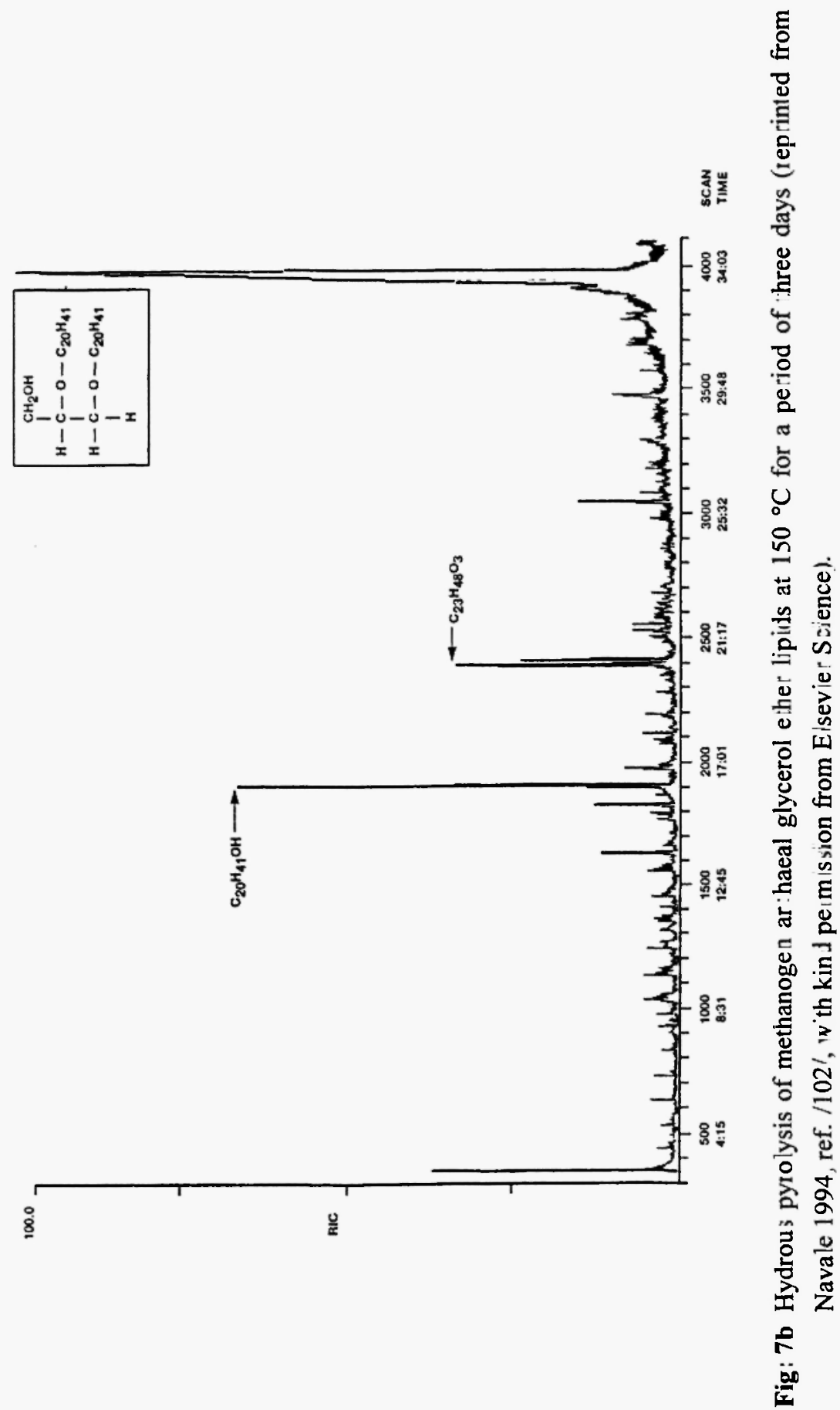


decyl)oxy]. It appears that hydrocarbon formation does not occur at a temperature of $150^{\circ} \mathrm{C}$; however, extending the time duration from three to sixty days may initiate its formation. Conversely, at $330^{\circ} \mathrm{C}$, a duration of three days is sufficient to initiate both $\mathrm{C}-\mathrm{O}-\mathrm{C}$ and $\mathrm{C}-\mathrm{C}$ bond cleavage. The reduction of alcohol to aldehyde and dehydration of alcohol to alkene are the likely pathways involved in the formation of 3,7,11,15-tetramethylhexadec-1-al and 3,7,11,15-tetramethyldec-1-ene, respectively. The formation of 2,6,10,14,-tetramethypentadecane may have resulted from loss of $\mathrm{CH}_{2} \mathrm{O}$ unit from the alcohol precursor. The thermal decomposition pathway and products of the methanogen archaeal GELs is provided in Figure 8. The

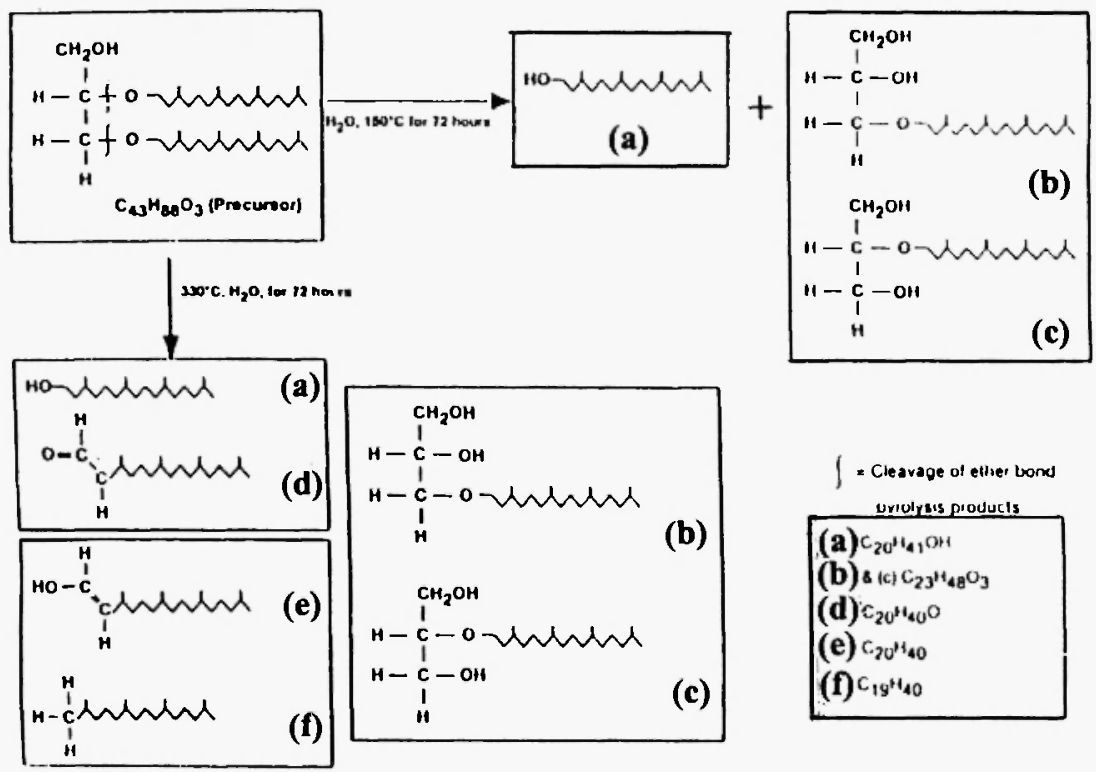

Fig. 8: Schematic representation of thermal decomposition pathway, and the products formed by hydrous pyrolysis of archaeal glycerol ether lipids at 330 and $150^{\circ} \mathrm{C}$ for time duration of three days, each. The pyrolysis products (a) $\mathrm{C}_{20} \mathrm{H}_{41} \mathrm{OH}, 3,7,11,15$-tetramethylhexadecan-1-ol, $\mathrm{C}_{23} \mathrm{H}_{48} \mathrm{O}_{3}$, monoalkyl glycerol ether isomers, (c) 1,3-propanediol-2-[(3,7,11,15-tetramethyl hexadecyl)oxy] and (b) 1,2-propanediol-3-[(3,7,11,15-tetramethyl hexadecyl)oxy], $\mathrm{C}_{20} \mathrm{H}_{40} \mathrm{O}, \quad 3,7,11,15$-tetramethylhexadecan-I-ol, (e) $\mathrm{C}_{20} \mathrm{H}_{40} \mathrm{O}$, 3,7,11,15-tetramethylhexadec-1-ene, (f) $\mathrm{C}_{19} \mathrm{H}_{40}, 2,6,10,14$,-tetramethylpentadecane (reprinted from Navale 1994, ref. /102/, with kind permission from Elsevier Science). 
identification of pyrolysis products from GELs showed that biological markers, when subjected to certain physico-chemical conditions, produce a mixture of organic compounds that can be correlated to the precursor biological molecules. However, with increasing thermal stress on the molecules, their structural information is progressively lost whereby the distinction between biological and abiological molecules becomes significantly minimized.

\section{CONCLUSION}

In the year 2004 and after, the first in-situ measurements of Titan's atmosphere may provide important information on the dynamics of planetary abiotic chemistry. The three GC columns on-board the Huygens GC-MS instrument will separate low molecular weight hydrocarbons, nitriles, and $\mathrm{CO}$ from a large background of nitrogen that is present in Titan's atmosphere. Ethane and ethene will be resolved on the low temperature glassy carbon phase column. By measuring the ratio of these components in samples collected at various altitudes, it may be possible to address an important fundamental question: does ethane condensation occur in Titan's atmosphere?

The mildly polar column containing the CPPS-DMPS stationary phase will separate the nitriles from the hydrocarbon homologues, and the separation of the BTX compounds will be facilitated by rapidly increasing the column temperature $\left(40\right.$ to $\left.60^{\circ} \mathrm{C}\right)$. Methane and $\mathrm{CO}$ will be resolved from a predominant nitrogen background by the micropacked porous carbon column.

Pyrolysis of archaeal GELs revealed a pathway for hydrocarbon formation. Milder thermal stress causes the dissociation of the ether bond, to form alcohols and monoalkyl glycerol ether lipids. At higher thermal stress, alcohol dehydration reaction may lead to the formation of hydrocarbons, and with increase in temperature, the $\mathrm{C}-\mathrm{C}$ bond scission progressively produces lower molecular weight hydrocarbons. The ratio of saturated to unsaturated hydrocarbon components produced may serve as an indicator of the thermal stress endured by the GEL molecule. Also, by studying the pyrolysis profile of archaeal GELs, the presence of dibiphytanyl GELs can be inferred, which is difficult to identify directly by the GC-MS method. In conclusion, pyrolysis techniques in combination with GC-MS may be a useful method for characterizing both abiological and biological processes operating in a natural environment. 


\section{ACKNOWLEDGEMENTS}

I thank Professor I. Schechter, Department of Chemistry, Israel Institute of Technology for inviting me to contribute a review on this topic. I am grateful to Dr. H. Niemann, Mr. D. Harpold and Mr. S. Way, Laboratory for Atmospheres, NASA-Goddard Space Flight Center, Greenbelt, Maryland for their insightful views on the Cassini-Huygens GC-MS work. I thank Professor A. Vertes, Department of Chemistry, The George Washington University for his thoughtful suggestions on the work. The support of Dr. D. Gilra of the Raytheon ITSS is acknowledged.

\section{REFERENCES}

I. J.C. Mather and J. Boslough in: The Very First Light: The True Inside Story of the Scientific Journey Back to the Dawn of the Universe, eds. J.C. Mather and J. Boslough, Basic Books Publishers, New York, 1996, p. 214.

2. P.J.E. Peebles, D.N Schramm, E.L Turner and R.G. Kron, in: The Big Bang and Other Explosions in Nuclear and Particle Astrophysics, ed. D.N. Schramm, World Scientific Publishing Co., 1996, p 11.

3. F. Matteucci, in: Chemistry in Space, eds. J.M.Greenberg and V. Pirronello, Kluwer Academic Publishers, Boston, 1991, p 1.

4. A. Dalgarno, in: Chemistry in Space, eds. J.M.Greenberg and V. Pirronello, Kluwer Academic Publishers, Boston, 1991, p 71.

5. J.F. Kasting, Science, 259, 920 (1993).

6. J.W. Schopf, in: Early Life on Earth, Nobel Symposium No. 84. ed. S. Bengston, Columbia University Press, New York, 1994, p193.

7. S.L. Miller, Science, 117, 351 (1953).

8. C. Ponnamperuma, in: Cosmochemistry and the Origin of Life, ed. C. Ponnamperuma, D. Riedel Publishing Company, 1983, p 1.

9. K. Kobayashi, T. Kaneko, M. Tsuchiya, T. Saito, T. Yamamoto, J. Koike and T. Oshima, Adv. Space. Res., 15,127 (1995).

10. J. Oro. Nature, 191, 1193 (1961)

11. C. Ponnamperuma, in: The Origins of Prebiological Systems and of their Molecular Matrices, ed. S.W. Fox, Academic Press, New York, 1965, p 221.

12. J. Oro, S. L. Miller and A. Lazcano, Annu. Rev. Earth Planet. Sci., 18, 317 (1990). 
13. W.R.Thompson, T.J. Henry, J.M. Schwartz, B.N Khare and C. Sagan, ICARUS, 90, 57 (1991).

14. S.W. Fox and K. Harada, Science, 128, 1214 (1958).

15. S.W. Fox and K. Dose, in: Molecular Evolution and the Origin of Life, eds. S. Fox and K. Dose, W.H. Freeman and Co., San Francisco, 1972, pl.

16. A. Schimpl, R.M. Lemmon and M. Calvin, Science, 147, 149 (1965).

17. C. Huber and G. Wächterhäuser, Science, 281, 670 (1998).

18. C. Ponnamperuma and R. Mack, Science, 148, 1221 (1965).

19. J. Oro, in: Early Life on Earth, Nobel Symposium No. 84., ed. S. Bengston,. Columbia University Press, New York, 1994, p 48.

20. S. Chang, in: The Chemistry of the Lifes's Origins, eds. J. M.Greenberg, C.X. Mendoza-Gomez and V. Pirronello, Kluwer Academic Publishers, Boston, 1993, p 259.

21. J. Oro, J. Biol. Physics, 20, 135 (1994).

22. D.W. Deamer, E. H. Mahon and G. Bosco, in Early Life on Earth, Nobel Symposium No. 84. ed. S. Bengston, Columbia University Press, New York, 1994, p 107.

23. J. Oro, in: Chemical Evolution: Physics of the Origin and Evolution of Life, ed. J. Chela-Flores and F. Raulin, Kluwer Academic Publishers, Boston, 1996, p3.

24. A. Leger, L. D'Hendecourt, L. Verstraete, and P. Ehrenfreund, in: Chemistry in Space. J.M.Greenberg and V. Pirronello, eds. Kluwer Academic Publishers: Boston, 1991, p 211.

25. J.R. Cronin and S. Chang, in: The Chemistry of Life's Origin. eds. J.M.Greenberg, C.X. Mendoza-Gomez, and V. Pirronello, Kluwer Academic Publishers, Boston, 1993, p 209.

26. D. S. McKay, E. K. Gibson, K. L. Thomas-Keprta, H. Vali, C.S. Romanek, S.J. Clemett, X.D.F. Chillier, C.R. Maechling and R.N. Zare, Science 273, 924 (1996).

27. D.W. Deamer, in: Life Sciences and Space Research XXIV (3), eds. J. Oro, G. Horneck, J.M. Greenberg, F. Raulin, A. W. Schwartz, K. Dose, and E.I. Friedmann, Pergamon Press, New York, 1991, p 183.

28. M.P. Bernstein, S.A. Stanford, L.J. Allmandola, J.S. Gillette, S.M. Clemett and R.N. Zare, Science, 283, 1135 (1999).

29. D.W. Deamer, E. H. Mahon and G. Bosco, in: Early Life on Earth, Nobel Symposium No. 84. S. Bengston, ed. Columbia University press, New York, 1994, p 107. 
30. M. Schidlowski, in: The Chemistry of Life's Origins, eds. J. M. Greenberg, C.X. Mendoza-Gomez and V. Pirronello, Kluwer Academic Publishers, Boston, 1993, p 389.

31. K.O. Stetter, in: Evolution of Hydrothermal Ecosystems on Earth (and Mars?), Ciba foundation Symp. No. 202. eds. G.R. Brock and J. A. Goode, Wiley Publishers, New York, 1996, p 1.

32. B.P. Tissot and D.H. Welte, in: Petroleum Formation and Occurrence, eds. B.P. Tissot and D.H. Welte, $2^{\text {nd }}$ edition, Springer-Verlag, New York, 1984, p 93.

33. W. Schimdt, in: Polycyclic Aromatic Hydrocarbons and Astrophysics, eds. A. Leger, L. d'Hendecourt and N. Boccara, NATO ASI Series C: Mathematical and Physical Sciences vol. 191, D. Riedel Publishing, 1987, p 149.

34. L. Becker, D.P. Glavin and J.L. Bada, Geochem. Cosmochim. Acta. 61, 475 (1997).

35. R. Summons and M.R.Walter, American. Jour. Science, 290-A, 212 (1990).

36. R.E. Summons, L.L. Jahnke and B.R.T. Simoneit, in: Evolution of Hydrothermal Ecosystems on Earth (and Mars?), Ciba foundation Symp. No. 202. eds. G.R. Brock and J. A. Goode, Wiley Publishers, New York, 1996, p174.

37. G. Ourisson, Pure. Appl. Chem., 62, 1401 (1990).

38. T.C. Hoering and V. Navale, Precambrian Res., 34, 247 (1987).

39. K. O. Stetter, in: Early Life on Earth, Nobel Symposium No. 84. ed. S. Bengston, Columbia University Press, New York, 1994 p 143.

40. M. De Rosa, A. Morana, A. Riccio, A. Gambacorta, A. Tricone and O. Incani, Biosens. \& Bioelectron., 9, 669 (1994).

41. W.M. McFadden in: Techniques of Combined Gas Chromatography/Mass Spectrometry, ed. W.M. McFadden, Wiley-Interscience Publication, New York, 1973, p 79.

42. G. Guiochon and C. L. Guillemin, in: Quantitative Gas Chromatography, eds. G. Guiochon and C. L. Guillemin, Elsevier, New York, 1988, p 531.

43. F.G. Kitson, B.S. Larsen and C.N. McEwen, in: Gas Chromatography and Mass Spectrometry, eds. F.G. Kitson, B.S.Larsen and C.N. McEwen, Academic Press, New York, 1996 pl.

44. J.T. Watson, in: Introduction to Mass Spectrometry, 3rd edition, ed. J.T Watson Lippincott-Raven Publishers, 1997, p 375. 
45. F.A. White and G. M. Wood, in: Mass Spectrometry: Applications in Science and Engineering, eds. F.A. White and G. M. Wood, Wiley-Interscience Publications, 1986, p 1.

46. M. Novotny, J.M. Hayes, F. Bruner and P.G. Simmonds, Science, 189, 215 (1975).

47. D.R. Rusneck, A.V. Diaz, D.W. Howarth, J. Rampacek, K.W Olson, W.D. Denker, P. Smith, L. McDavid,.; A. Tomassian,.; M. Harris,.K. Bulota,.; K. Biemann, A. L. LaFleur, J.E. Biller and T . Owen, Rev. Sci. Instrum., 49, 817 (1978).

48. F. Raulin, E. de Vanssay, L. Do, and P. Paillous,. LCGC, 5 (Intl. Vol.), 22 (1993).

49. J.V. Hinshaw, L.S. Ettre, in: Introduction to Open-tubular Column Gas Chromatography, eds. J.V. Hinshaw and L. S. Ettre, Advanstar Communications, Clevland, Ohio, 1994, p 1

50. L. Do and F. Raulin, J. Chromatogr., 481, 45 (1989).

51. L. Do and F. Raulin, J. Chromatogr., 514, 65 (1990).

52. E. de Vanssay, P. Capilla, D. Coscia, L. Do, R. Sternberg and F. Raulin, J. Chromatogr., 639, 255 (1993).

53. L. Do and F. Raulin, J. Chromatogr., 591, 297 (1992).

54. A. Aflalaye, R. Sternberg, F. Raulin and C. Vidal-Madjar, J. Chromatogr., 708, 283 (1995).

55. J.I. Lunine, S.K. Atreya and J.B. Pollack in: Origin and Evolution of Planetary and Satellite Atmospheres. eds. S.K. Atreya, J.B. Pollack and M.S. Matthews, The University of Arizona Press, 1989, p 605.

56. T. Owen, D. Gautier, F. Raulin and T. Scattergood, in: Exobiology in Solar System Exploration. eds. G.C. Carle, D.E. Schwartz and J. Huntington, NASA Special Publication (SP) 512, 1992, p127.

57. S.J. Kerridge, W. Flurry, L. J. Horn, J.P. LeBreton, D.S. Stetson, R.L. Stoller and G.H.Tan, in: Exobiology in Solar System Exploration. eds. G.C. Carle, D.E. Schwartz and J. Huntington, NASA Special Publication (SP) 512, 1992, p 229.

58. F. Raulin, C. Frere, P. Paillous, E. de Vanssay, L. Do and M. Khilfi, Jour. British. Intl. Planet. Soc., 45, 257 (1992).

59. H. B. Niemann, in: Gas Chromatograph Mass Spectrometer for the Huygen's probe, European Space Agency (ESA)-SP-1177, 1997, p 85.

60. A. Schuyler and M.J. Feeney LC-GC, 13, 780 (1995).

61. A. Aflalaye, S. Anguel, R. Sternberg, F. Raulin and C. Vidal-Majdar, Jour. Chromatogr., 746, 63 (1996). 
62. D. Albaiu, The Ohio State University, personal communication, 1996.

63. T. M. Engel, S. V. Olesik, M.R. Callstrom and M. Diener, Anal. Chem., 65, 3691 (1994).

64. G. Israel, in: Aerosol Collector Pyrolyzer for the Huygen's probe, European Space Agency (ESA)-SP-1177, 1997, p 59.

65. L. Rohrschneider, LC-GC, 11, No. 10 (1993).

66. W. J. Jennings, J. Chromatogr. Sci., 28, 385 (1990).

67. R. A. Mowery, Jr. J. Chromatogr. Sci., 29, 194 (1991).

68. V. Navale, D. Harpold and A. Vertes, Anal. Chem., 70, No. 4, 689 (1998).

69. R. Sternberg, C. Szopa, D. Coscia, S. Zubrzycki, F. Raulin, C. Vidal-Madjar, H. Niemann and G. Israel, J. Chromatogr. A, 846, 307 (1999).

70. C.C. Parrish, Mar. Chem. 23, 17 (1988).

71. G. Ourisson, in: Early Life on Earth, ed. S. Bengston, Nobel Symposium No 84. Columbia University Press, New York, 1994, p259.

72. H.R. Harvey, R.D. Fallon and J.S. Patton, Geochem. Cosmochim. Acta, 50, 95 (1986).

73. S.C Brassel and G. Eglinton, in: Organic Marine Geochemistry, ed. M.

L. Sohn, American Chemical Society (ACS) Publication, Washington DC 1986, p 10.

74. P.A. Comet and G. Eglinton, in: Marine Petroleum Source Rocks, eds. J. Brooks, A. J. Fleet, Geological Society special Publication No. 26, 1987, p99.

75. C.R. Woese, Microbio. Rev. 51, 221(1987).

76. R.P. Pool, Science, 247, 158 (1990).

77. M. Kates, Biochem. Soc. Symp., 58, 51 (1992).

78. G. G. Pauly and E.S. Van Vleet, Org. Geochem., 10, 859 (1986).

79. S. N. Sehgal, M Kates and N. E. Gibbons, Can. J. Biochem. Physiol., 40, 69 (1962).

80. M. DeRosa, A. Gambacorta and A. Gliozzi, Microbio. Rev., 50, 70 (1986).

81. D.H. Hedrick, D.E. Nivens, C. Stafford and D.C. White, J. Microbiol. Method, 13, 67 (1991).

82. C. A. Mancuso, G. Odham, G. Westerdahl, J. N. Reeve and D.C. White, J. Lipid Res., 26, 1120 (1985). 
83. D.H. Hedrick, J.B.Guckert and D.C. White, J. Lipid. Res., 32, 659 (1991).

84. C.A. Mancuso, P.D. Nichols and D.C. White, J. Lipid. Res., 27, 49 (1986).

85. K.D. Kloppel and H. L. Fredrickson, J. Chromatogr., 562, 369 (1991).

86. G. D. Sprott, J. Bioenerg, Biomemb. 24, 555 (1992).

87. A.P. Synder, P.B.W. Smith, J.P. Dworzanski and H.L.C. Meuzelaar, in: Mass Spectrometry for Characterization of Microorganisms, ed. C. Fenselau, American Chemical Society (ACS) Symposium Series 541, 1994, p 62.

88. R.P. Philip, J. Anal. Appl. Pyrol., 11, 93 (1987).

89. B. Horsefield, Geochem. Cosmochim. Acta., 53, 891 (1989).

90. K.E. Peters, J.M. Moldowan and P. Sundaram, Org. Geochem. 15, 249 (1990).

91. S.L. Lu, E. Ruth and I.R. Kaplan, Org. Geochem., 14, 491 (1989).

92. F. Bertini, G. Audisio, P.L. Beltrame, L. Bergamasco and A. Castelli, J. Appl. Poly. Sci., 70: (11), 2291 (1998).

93. T..M. Collum, B.R.T. Simoneit, E.L. Shock, Energy \& Fuels, 13: (2), 401 (1999).

94. T. P. Wampler in: Applied Pyrolysis Handbook. ed. T.P. Wampler, Marcel Dekker Inc., New York, 1995, p 31.

95. E. J. Levy and J.Q. Walker, J. Chromatogr. Sci. 22, 49 (1984).

96. V. Navale, J. Anal. Appl. Pyrol. 24, 301 (1993).

97. R. A. Brown, Anal. Chem., 43, 900 (1971).

98. V. Navale, J. Anal. Appl. Pyrol. 23, 121 (1992).

99. T.K. Pease, E.S. Van Vleet, J.S. Barre and H.D. Dickens, Org. Geochem. 29, 979 (1998).

100. Wampler, T. J. Anal. Appl. Pyrol. 15, 187 (1989).

101. S.J. Rowland, Org. Geochem., 15, 9 (1990).

102. V. Navale, J. Anal. Appl. Pyrol. 29, 33 (1994)

103. J.W Smith, B.D Batts and T.D. Gilbert, Org. Geochem. 14, 365(1989). 